\title{
REGIONAL CLIMATE-WEATHER RESEARCH AND FORECASTING MODEL
}

\author{
by Xin-Zhong liang, Min Xu, Xing Yuan, Tiejun Ling, Hyun I. Chol, Feng Zhang, ligang Chen, \\ Shuyan liu, Shenjian Su, Fengxue Qiao, Yuxiang He, Julian X. L. Wang, Kenneth E. Kunkel, \\ Wei Gao, Everette Joseph, Vernon Morris, Tsann-Wang Yu, Jimy Dudhia, and John Michalakes
}

\section{An extension of the WRF, incorporating a comprehensive ensemble of alternative physics representations, facilitates seamless applications for regional weather forecasting and climate prediction.}

$R$ CMs (see the appendix for expanded acronyms) have been widely applied and well recognized as an essential tool to address scientific issues concerning climate variability, changes, and impacts at regional-local scales (Giorgi and Mearns 1999; Giorgi et al. 2001; Leung et al. 2003; Wang et al. 2004; Giorgi 2006; Fowler et al. 2007; Christensen et al. 2007; Bader et al. 2008; Liang et al. 2008a,b). Numerous RCMs have been developed that demonstrate useful downscaling skill, and yet many model deficiencies remain to be resolved. The most commonly used RCMs have been based on various versions of the Pennsylvania State University/NCAR Mesoscale Model (Anthes et al. 1987; Grell et al. 1994; Dudhia et al. 2005); this model family has now been superseded by the WRF (Skamarock et al. 2008). Accordingly, we have undertaken a lengthy
AFFILIATIONS: LIANG-Departments of Atmospheric and Oceanic Science and Earth System Science Interdisciplinary Center, University of Maryland, College Park, College Park, Maryland, and Illinois State Water Survey and Department of Atmospheric Sciences, University of Illinois at Urbana-Champaign, Urbana, Illinois; Xu, Zhang, CHen, LIU, AND SU-Earth System Science Interdisciplinary Center, University of Maryland, College Park, College Park, Maryland, and Illinois State Water Survey, University of Illinois at Urbana-Champaign, Urbana, Illinois; YUAN_Illinois State Water Survey, University of Illinois at Urbana-Champaign, Urbana, Illinois, and Department of Civil and Environmental Engineering, Princeton University, Princeton, New Jersey; LING-Illinois State Water Survey, University of Illinois at Urbana-Champaign, Urbana, Illinois, and Key Laboratory of Research on Marine Hazards Forecasting, National Marine Environmental Forecasting Center, Beijing, China; $\mathrm{CHOl}$ - Illinois State Water Survey, University of Illinois at Urbana-Champaign, Urbana, Illinois, and Department of Civil Engineering, Yeungnam University, Daegu, South Korea; QIAO-IIlinois State Water Survey, and Department of Atmospheric Sciences, University of Illinois at Urbana-Champaign, Urbana, Illinois; HE-Earth System Science Interdisciplinary Center, University of Maryland, College Park, College Park, Maryland; WANG - NOAA/Air Resources Laboratory, Silver Spring, Maryland; KUNKEL-Cooperative Institute for Climate and Satellites, North Carolina State University, and NOAA/National Climatic Data
Center, Asheville, North Carolina; GAO_USDA UV-B Monitoring and Research Program, Natural Resource Ecology Laboratory, and Department of Ecosystem Science and Sustainability, Colorado State University, Fort Collins, Colorado, and Key Laboratory of Geographic Information Science, East China Normal University, Shanghai, China; JOSEPH, MORRIS, AND YU-Department of Physics and Astronomy, Howard University, Washington, D.C.; DUDHIA AND MiCHALAKEs*_-Mesoscale and Microscale Meteorology Division, NCAR, Boulder, Colorado

*CURRENT AFFILIATION: National Renewable Energy Laboratory, Golden, Colorado CORRESPONDING AUTHOR: Dr. Xin-Zhong Liang, Earth System Science Interdisciplinary Center, University of Maryland, College Park, 5825 University Research Court, Suite 400I, College Park, MD 20740

E-mail: xliang@umd.edu

The abstract for this article can be found in this issue, following the table of contents.

DOI:10.1175/BAMS-D-II-00180.1

A supplement to this article is available online (DOI:10.I175/BAMS-

D-II-00180.2)

In final form 24 February 2012

(C)2012 American Meteorological Society 
effort to develop a version of WRF (CWRF) specifically improved for climate time-scale applications. The most crucial improvements targeted interactions between land, atmosphere, and ocean; convection and microphysics; and cloud, aerosol, and radiation, as well as system consistency throughout all process modules (Liang et al. 2002, 2004c, 2005b,d,a,c, 2006b; Xu et al. 2005; Choi 2006; Choi et al. 2007; Choi and Liang 2010; Yuan and Liang 2011a).

The WRF was designed originally for short-range NWP but not expressly for long-term climate simulation. There has been some success using WRF for regional climate downscaling with a continuous model integration of longer than a season (Liang et al. 2002; Leung and Qian 2009; Evans and McCabe 2010; and all the following references cited in this paragraph). Such direct applications, however, also have encountered numerous problems. These include 1) degradation of summer daily rainfall variations over China by downscaling (Wang and Yang 2008); 2) strong overprediction (underprediction) of winter precipitation intensity (frequency), and large warm biases in summer surface temperature along with low estimates of soil moisture over California (Caldwell et al. 2009); 3) notable warm biases in surface daily minimum temperature in winter and autumn, and low correlations between modeled and observed daily precipitation over the U.S. Pacific Northwest (Zhang et al. 2009); 4) precipitation overestimation over West Africa (Druyan et al. 2009; Vigaud et al. 2011); and 5) excessive rainfall at off-equatorial latitudes and a deficit near the equator (Tulich et al. 2011). To remedy unsatisfactory predictive skill scores, Lo et al. (2008) suggested more frequent reinitialization or stronger 3D observational nudging; Heikkilä et al. (2011) sought after domainwise spectral nudging to maintain the large-scale feature; Bukovsky and Karoly (2009) recommended careful scrutiny of model consistencies; and Chin et al. (2010), Mukhopadhyay et al. (2010), Awan et al. (2011), Crétat et al. (2012), and Flaounas et al. (2011) emphasized model sensitivities to different physics schemes. Even using a daily initialization, Hines et al. (2011) found that WRF still produces warm temperature biases in winter and summer and a marked summer cloud cover deficit with excessive incident shortwave radiation over the western Arctic. None of these studies focused on the systematic development of improved physics representations that are suitable for climate prediction at certain resolutions. This is the key goal of the CWRF development.

The CWRF has been built on three main principles. First, CWRF is an extension of WRF, inheriting all WRF functionalities for NWP while enhancing its capability to predict climate. As such, CWRF can be applied to both weather forecasting and climate prediction (e.g., Zeng et al. 2008a,b; Liu et al. 2008). This unification offers an opportunity to develop, test, and verify new physical parameterizations of unresolved processes, identify their systematic errors, and eventually improve them over a wide range of phenomena, from weather to climate scales. Incorporation of the WRF data assimilation system enables CWRF to produce short-range weather forecasts from realistic initial conditions. High-frequency NWP analyses and unassimilated observations can be used to identify and correct parameterization deficiencies, resulting in improvements initially manifested in short-range weather forecasts and then persisted in climate simulations (Phillips et al. 2004). In contrast, some systematic climate biases that develop slowly probably cannot be identified and removed by the NWP-based approach (Liang et al. 2005c; Bukovsky and Karoly 2009). Clearly, CWRF provides a unique tool to develop improved schemes for realistic and seamless prediction of weather and climate, which were declared as both necessary and possible at the recent World Modelling Summit for Climate Prediction (Shukla et al. 2009).

Second, CWRF provides a multimodel ensemble prediction capability by incorporating a comprehensive list of alternative parameterization schemes for each of the key physical processes, including surface (land, ocean), PBL, cumulus (deep, shallow), microphysics, cloud, aerosol, and radiation. The CWRF currently contains over $10^{24}$ configurations representing these processes and their interactions, which we believe is the largest among existing weather/ climate modeling systems. Different schemes were designed with different conceptual underpinnings and tunable parameters that are not universal and are also quite uncertain (Arakawa 2004). No single scheme performs uniformly well under all conditions, and each has predictive ability highly dependent on weather or climate regimes (Tselioudis and Jakob 2002; Liang et al. 2004a,b; Mapes et al. 2004; Jankov et al. 2005; Gallus and Bresch 2006; Zhu and Liang 2007) and application scales (Kiehl and Williamson 1991; Dudek et al. 1996; Giorgi and Marinucci 1996; Jung and Arakawa 2004; Hack et al. 2006). Thus, consensus weather and climate predictions based on an ensemble of multiple physics configurations of a model or multiple models have recently been highlighted for their superior skills over those using a single configuration or model (Krishnamurti et al. 2000; Palmer et al. 2004; Gleckler et al. 2008; Kirtman and Min 2009). Such superiority is realized because 
distinct regions are identified where each model or scheme complementarily captures certain but not all observed signals. Our recent research suggests that better prediction, especially for precipitation, is achievable through intelligent optimization of the model physics ensemble (Liang et al. 2007; Zeng et al. 2008a; Liu et al. 2009). The CWRF physics ensemble, when optimized against observations, will result in improved weather or climate prediction at regionallocal scales.

Third, CWRF emphasizes a societal service capability to provide credible information for climate impacts and risk analyses. The CWRF development has included an effort to incorporate modules designed to address certain specific needs of stakeholders for quantitative information on natural resource changes at regional-local scales. In this regard, we have built additional component models that are capable of predicting terrestrial hydrology (Choi 2006; Choi et al. 2007; Choi and Liang 2010; Yuan and Liang 2011a), upper-ocean processes (Ling et al. 2011), air quality (Huang et al. 2007; Wang et al. 2010), UV radiation (Xu et al. 2006), and crop growth (Xu et al. 2005; Liang et al. 2012a,b). The last two modules and others (e.g., water quality, ecosystem) have been evaluated in standalone mode and are being coupled with CWRF. The optimal use of such output by decision makers requires not only accurate predictions of key surface quantities (temperature, precipitation, soil moisture, streamflow, runoff, water table, crop yields, pollutants, UV levels, etc.), including their means and extremes, but also reliable estimates of corresponding uncertainties, especially in projecting future climate change. The CWRF physics ensemble offers a pragmatic approach to achieve that goal. Weighting individual members by their skill in resolving past observations can provide strong constraints on the ensemble prediction of future outcomes (Murphy et al. 2004; Palmer et al. 2008), although how to apply the constraints is still a matter of debate (Scaife et al. 2009; Palmer et al. 2009).

The CWRF improvements have been accomplished through iterative, extensive model refinements, sensitivity experiments, and rigorous evaluations over the past 8 yr. As a result, CWRF has demonstrated greater application capability than the original WRF and overall better performance in simulating the U.S. regional climate than the existing CMM5 (Liang et al.
2001, 2004b, 2007; Zhu and Liang 2005, 2007). This justifies its initial release for community use. A series of papers being prepared will document details of the CWRF formulations as well as weather forecast and climate prediction skill. The present study provides a general model description and a basic evaluation of model skill using a continuous CWRF integration for the period 1979-2009 as compared with those of CMM5 and WRF. All models were run on an identical U.S. computational domain of $30-\mathrm{km}$ grid spacing (Liang et al. 2004b) and driven by the same global R-2 (Kanamitsu et al. 2002), one of the best available proxies for observations. These integrations are also compared with a similar run, named WRFG, which uses the earlier WRF version 2 over an extended domain and relatively coarse $50-\mathrm{km}$ grid spacing (Leung et al. 2011) as a part of the NARCCAP effort (Mearns et al. 2012). These comparisons depict the critical dependence of the RCM climate downscaling skill on the model configurations for physics, resolution, and domain.

BRIEF MODEL DESCRIPTION. Figure 1 illustrates the current CWRF physics options and executing structure. There are seven major drivers, each of which controls multiple alternative schemes for the physical processes of cloud, aerosol, radiation, surface, PBL, cumulus, and microphysics, in the sequential order of computation. The first three drivers (cloud, aerosol, radiation) form the CAR ensemble modeling system that incorporates over $10^{18}$ different ways to simulate interactions among cloud, aerosol, and radiation, developed from seven packages available in the leading global and regional models around the world. This replaces the original WRF single radiation driver that consists of the $\mathrm{CAM}^{1}$ and AER packages, along with the now-obsolete MISC schemes. The surface driver manages all schemes handling surface and subsurface processes over land and oceans, as well as surface-atmosphere flux exchanges. In particular, CWRF adds the advanced CSSP and CROP for terrestrial hydrology and crop growth over land, and SOM and UOM for mixed-layer and upper-ocean effects. The two urban schemes are separated from Noah and now work with all land surface schemes. All seven surface layer schemes, originally tied to specific options, are now interchangeable for all surface and $P B L$ schemes. The

\footnotetext{
${ }^{1}$ For the purpose of conciseness, this paper uses many abbreviations and acronyms. All the physics schemes actually used in this study with their respective references are listed in the supplementary material or otherwise listed in the appendix of this paper. Note also that several schemes, including AER and FLG radiation and UW and ZML cumulus, have been added to the latest WRF release. They are, however, implemented differently with numerous variations in CWRF.
} 


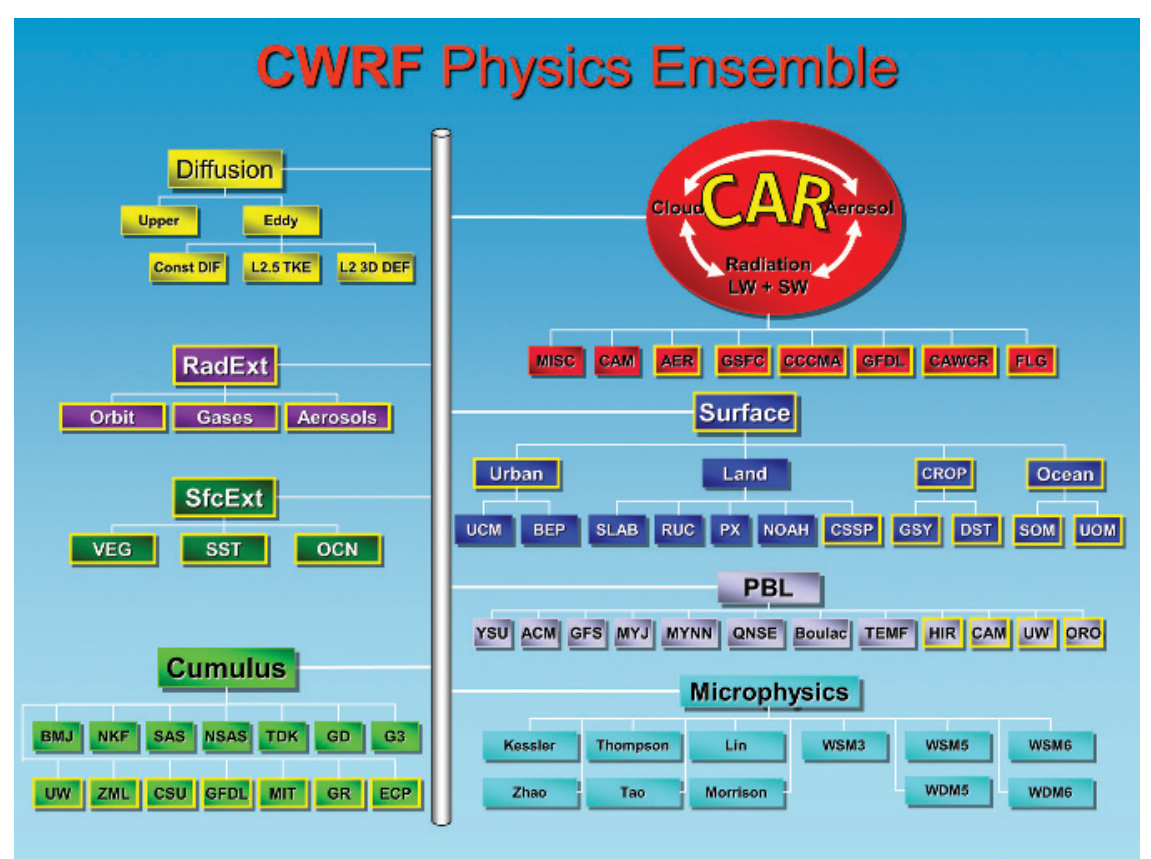

FIG. I. The schematic of the current CWRF physics options and executing sequence from the top-down. The CAR ensemble system and all modules or schemes outlined in yellow are additions specifically developed for CWRF, while others are inherited from WRF.

PBL driver hosts seven WRF plus two new (CAM, UW) PBL schemes, all of which are integrated with the ORO, accounting for orographic turbulence stress and gravity wave drag. The cumulus driver provides the hub for seven WRF plus six new (GR, ZML, CSU, GFDL, MIT, ECP) deep cumulus schemes, all of which can be coupled with a shallow convection scheme (UW). A consistent switch is added to control whether shallow convection is activated internally in eight deep cumulus schemes or done externally by the UW scheme. The microphysics driver incorporates the 11 microphysics schemes of WRF.

Of central importance, we strove to make all alternative schemes in CWRF fully coupled across all drivers with plug-and-play interfaces. Even without counting the grand CAR ensemble, CWRF currently contains over $10^{6}$ configurations for the surface, PBL, cumulus, and microphysics processes and their interactions. To achieve this, substantial efforts were made to scrutinize all individual schemes for consistency and incorporate suitable algorithms for missing variables to enable the coupling for the overall system. Particular care has been taken to ensure continuous model integration that can be restarted at any interval while resulting in bit-bybit numerical agreement. This is not trivial, especially if time-step intervals differ among executing individual physics drivers. A seamless averaging procedure is implemented to replace prognostic cumulative variables by their averages between two consecutive steps of the driver at work during the integration. This is especially effective for precipitation fields (convective/resolved rainfall/snowfall) that are used for different purposes in the cumulus, microphysics, surface, cloud, and aerosol drivers. Other diagnostic cumulative variables, such as surface water and energy budget fields, can be set to zero at any restart checkpoint to reduce truncation errors. As such, CWRF can be run reliably for a long-term climate simulation with frequent restarts as needed and with varying time steps for all seven physics drivers. In contrast, $\mathrm{WRF}^{2}$ with several tested configurations has been reported to result in numerical instability or serious drift that prohibits its use for continuous climate-scale simulations.

The CWRF has improved WRF with major advances in the integration of external (top, surface, lateral) forcing conditions and in the representation of physical processes that are essential to climate modeling. These improvements have been implemented mostly as "plug-compatible physics," and thus will not cause any problem with parallelism and supercomputing optimization in general. All the new schemes in CWRF are summarized in the supplementary material (http:// dx.doi.org/I0.II75/BAMS-D-II-00|80.2), while those of the original WRF are referenced in Skamarock et al. (2008) and Wang et al. (2012).

\section{MODEL EXPERIMENT DESIGN AND} EVALUATION DATA. The CWRF computational domain for this study (Fig. 2) is centered at $37.5^{\circ} \mathrm{N}$,

\footnotetext{
${ }^{2}$ Note that the WRF can be configured to many versions using different combinations of physics schemes. The reported WRF configurations are limited. The statement was drawn from our own experience with the WRF runs and through review of several journal manuscripts of others.
} 
$95.5^{\circ} \mathrm{W}$, covers the entire continental United States with $30-\mathrm{km}$ grid spacing, and represents regional climate variations that result from interactions with the planetary circulation (as forced by LBCs) and North American surface processes, including orography, soil, vegetation, and coastal oceans. The buffer zones are located across 14 grids along four edges of the domain, where varying LBCs are specified through a dynamic relaxation technique (Liang et al. 2001). This domain design has produced skillful simulations of U.S. precipitation, surface temperature, and soil moisture (Liang et al. 2004a,b, 2005c, 2006a,b, 2007; Zhu and Liang 2005, 2007). Also displayed in Fig. 2 are the land cover and ocean depth distributions, lakes, major rivers, and main streams as well as the Corn/Soybean and Cotton Belts. These fields are a small subset of the comprehensive SBCs used by CWRF (Liang et al. 2005b,d, 2012a).

Table 1 summarizes the key model configuration differences of the CWRF simulation from those of WRF, WRFG, and CMM5 to be compared. All simulations are driven by the R-2 LBCs, while the integration length varies. This study compares the model performance in the common period, from 1 January 1982 to 31 December 2004.

The WRF and CMM5 runs are done over an identical domain with the same horizontal grid as CWRF, whereas the WRFG run is made over a larger domain (North America) with a coarser grid $(50 \mathrm{~km})$. The buffer zone, where the LBCs are dynamically relaxed with linearexponential nudging coefficients, has a comparable width among the runs. The CMM5 uses a lower vertical resolution than others. Important differences exist in the physics configuration. In particular, CWRF incorporates several newly developed and more advanced schemes, including those for radiation, surface (land and ocean), and cumulus (deep and shallow) processes. Note that the PBL schemes (CAM, YSU, MRF) are similar in both physical formulation and skill performance (via offline test), while the CAM radiation, Noah surface, GSFC GCE microphysics, and G3 cumulus are the updated CCM2, OSU, GSFC, and GD (rooted from GR) versions, respectively. As such, this collection of simulations represents a comparison of the physics schemes that are most relevant among the RCMs with available long integrations of the same kind.

Given that RCM downscaling skill is sensitive to large-scale forcing errors (e.g., Liang et al. 2001), an additional CWRF integration during 1989-2010 driven by the LBCs from the recently available ERI (Uppala et al. 2008) is conducted and compared with the control run to explain certain systematic model departures from observations (see below).

For model evaluation, daily total precipitation and daily mean (average of maximum and minimum) surface air temperature (at the screen height of 1.25-2 $\mathrm{m}$ above the ground) data are based on measurements from 7,235 National Weather Service cooperative stations across the United States. They are mapped onto the CWRF grid following the objective analysis of Liang et al. (2004b) with the topographic adjustment of Daly et al. (2008). The station density

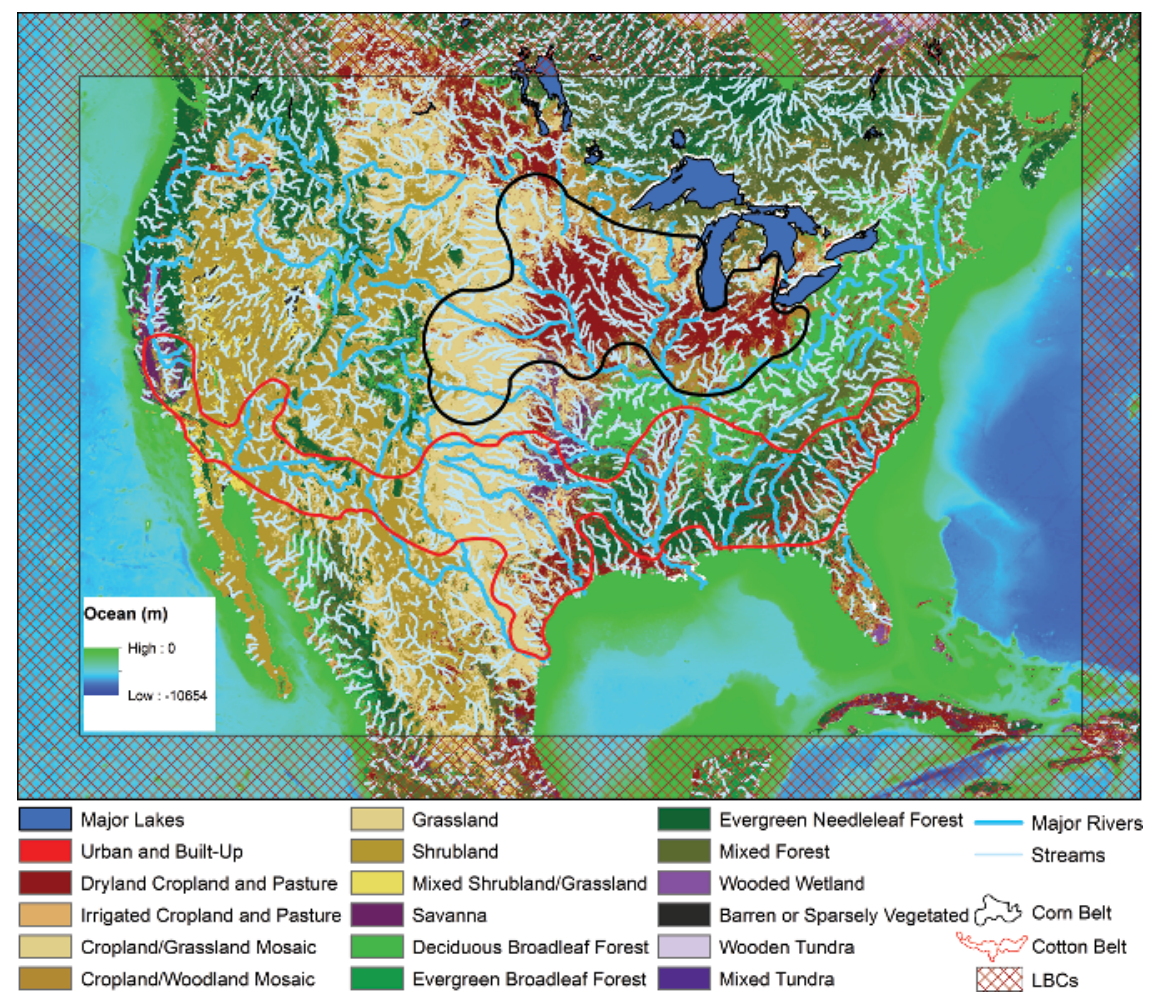

FIG. 2. The CWRF computational domain for this study. The hatched edge areas are the buffer zones, where LBCs are specified. Overlaid are the geographic distributions of land cover (USGS 24 categories) and ocean depth $(\mathrm{m})$, lakes, major rivers, and main streams as well as the outlines of the Corn/ Soybean and Cotton Belts. 


\begin{tabular}{|c|c|c|c|c|c|}
\hline \multicolumn{2}{|c|}{ RCM name } & CWRF & WRF & WRFG & CMM5 \\
\hline \multicolumn{2}{|c|}{ Key reference } & Liang et al. (2012) & Skamarock et al. (2008) & Leung et al. (20II) & Liang et al. $(2004 a, b)$ \\
\hline \multicolumn{2}{|c|}{ Model version } & CWRF version 3.I.I & WRF version 3.I.I & WRF version 2.0 .1 & CMM5 version 3.3 \\
\hline \multicolumn{2}{|l|}{ Domain } & United States and adjacent & United States and adjacent & North America & United States and adjacent \\
\hline \multirow{2}{*}{ Resolution } & Horizontal & 30 km $(196 \times 136)$ & 30 km (196 x 136) & $50 \mathrm{~km}(155 \times 130)$ & 30 km (196 x 136) \\
\hline & Vertical & 36 levels, top at $50 \mathrm{hPa}$ & 36 levels, top at $50 \mathrm{hPa}$ & 35 levels, top at $50 \mathrm{hPa}$ & 23 levels, top at $100 \mathrm{hPa}$ \\
\hline \multicolumn{2}{|c|}{ Buffer zone width (km) } & 14 grids $(420)$ & 14 grids $(420)$ & 10 grids $(500)$ & 14 grids $(420)$ \\
\hline \multicolumn{2}{|c|}{ Integration period } & I Jan |979-3I Dec 2009 & I Jan |979-3I Dec 2009 & I Sep |979-3| Dec 2004 & 2 Dec 198I-3I Dec 2009 \\
\hline \multirow{7}{*}{ 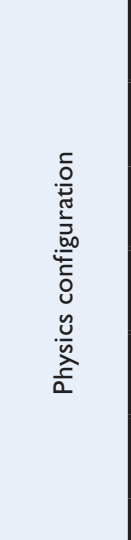 } & Radiation & $\begin{array}{l}\text { GSFC (Chou and Suarez } \\
\text { 1999; Chou et al. 200I) }\end{array}$ & CAM (Collins et al. 2004) & CAM (Collins et al. 2004) & CCM2 (Hack et al. 1993) \\
\hline & Surface & CSSP (Choi 2006) & Noah (Ek et al. 2003) & Noah (Ek et al. 2003) & $\begin{array}{l}\text { OSU (Chen and Dudhia } \\
\text { 200I) }\end{array}$ \\
\hline & PBL & $\begin{array}{l}\text { CAM (Holtslag and Boville } \\
\text { 1993) }\end{array}$ & YSU (Hong et al. 2006) & YSU (Hong et al. 2006) & MRF (Hong and Pan 1996) \\
\hline & Cumulus & ECP (modified G3) & G3 (new GD) & $\begin{array}{l}\text { GD (Grell and Dévényi } \\
\text { 2002) }\end{array}$ & GR (Grell 1993) \\
\hline & Microphysics & $\begin{array}{l}\text { GSFC GCE (Tao et al. } \\
2003 \text { ) }\end{array}$ & WSM5 (Hong et al. 2004) & WSM5 (Hong et al. 2004) & $\begin{array}{l}\text { GSFC (Tao and Simpson } \\
\text { 1989) }\end{array}$ \\
\hline & Shallow $\mathrm{Cu}$ & $\begin{array}{l}\text { UW (Park and Bretherton } \\
\text { 2009) }\end{array}$ & None & None & None \\
\hline & Ocean/lake & Multilevel models & None & None & None \\
\hline
\end{tabular}

is generally high and compatible with the CWRF $30-\mathrm{km}$ grid except for mountainous regions in the Rockies. Over Canada and Mexico, precipitation and temperature data are based on the NOAA/CPC $0.5^{\circ}$ daily analysis (Chen et al. 2008) and the CRU TS3.0 $0.5^{\circ}$ monthly mean analysis ( $w w w . c r u . u e a . a c . u k / c r u$ $/ \mathrm{data} / \mathrm{hrg} /$ ), respectively, both from station measurements and with no topographic adjustment. Data for surface downwelling shortwave radiation flux are taken from the ISCCP satellite $280-\mathrm{km}$ monthly mean product available from July 1983 onward. These global analysis data are mapped onto the CWRF $30-\mathrm{km}$ grid using bilinear spatial interpolation to supplement corresponding values beyond the U.S. land area.

\section{CWRF PERFORMANCE ON SEASONAL} VARIATION. Figure 3 compares the geographic distributions of 1982-2004 averaged seasonal mean precipitation as observed and simulated by CWRF, WRF, WRFG, and CMM5. Observed precipitation amounts are relatively high along the West Coast (except during summer) and east of about $100^{\circ} \mathrm{W}$ and relatively low in the western intermountain area and just east of the Rocky Mountains. All RCMs accurately simulate the dry zone transition that arises from precipitation shadowing by the mountain ranges. West of that zone, two distinct precipitation regimes occur: a cold-season maximum in the Northwest and a warm-season maximum in the Southwest. East of that zone, there exist two major precipitation regimes with a rather even seasonal distribution in the Midwest and the Gulf states. These four regimes are governed by distinct physical processes, for which the RCMs' skills vary significantly and thus are summarized as follows. To facilitate the interpretation of the results, Fig. 4 illustrates the annual cycles of model precipitation biases (departures from observations) along with observations as averaged over the four key regions representative of the four systems.

Over the Northwest, all RCMs capture the observed precipitation mesoscale patterns and their seasonal variations rather well. Precipitation is a maximum over the west slopes of all major mountain ranges, peaks in winter, decreases in spring and autumn, and diminishes in summer. Cold-season (September-May) precipitation over the Cascade Range is overestimated by CWRF and WRF but is realistically simulated by WRFG and CMM5. Precipitation there is dominated by large-scale forcing associated with orographic uplift within the eastward-moving Pacific storm systems. Hence, the contribution from the subgrid convective process is 

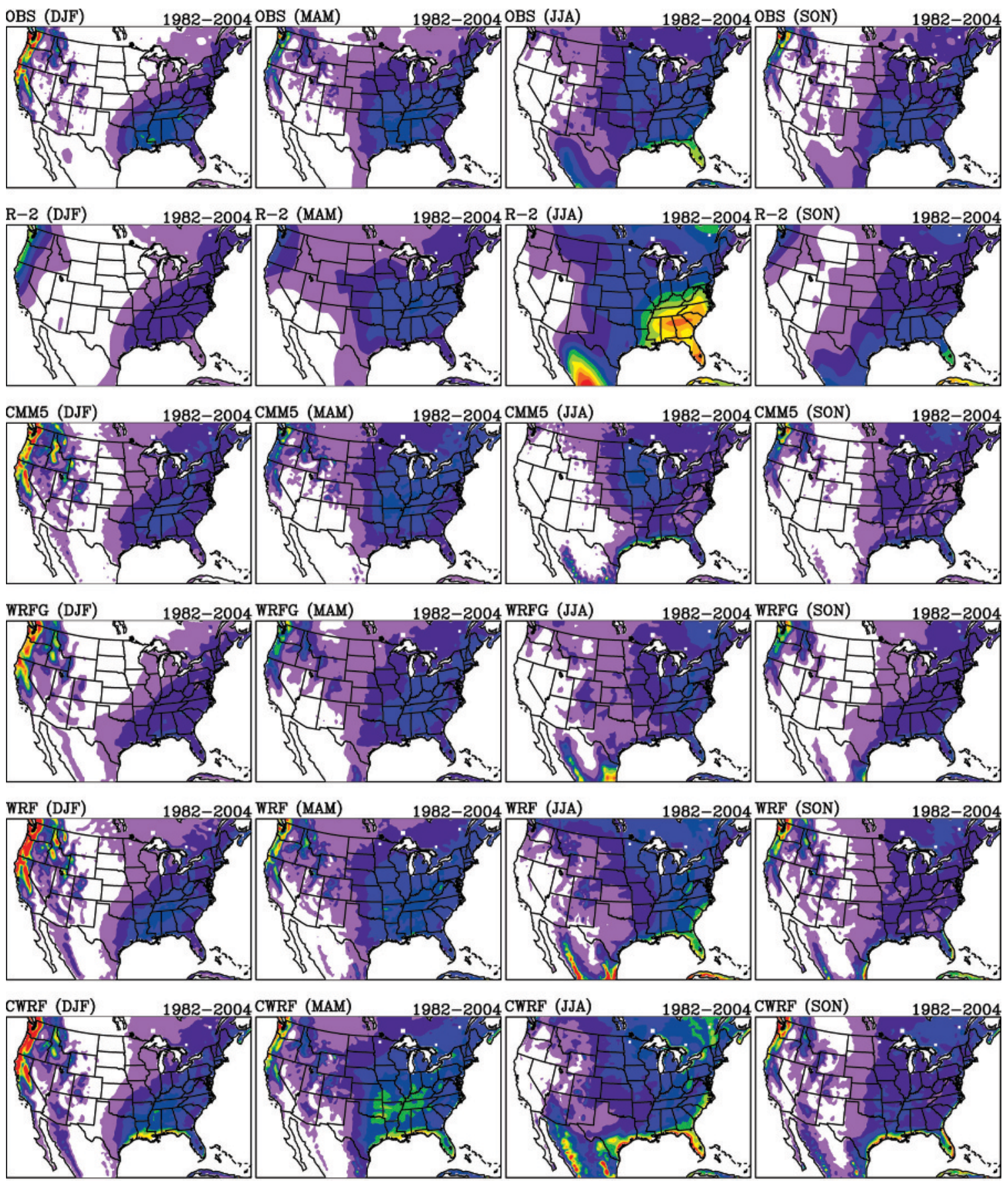

CWRF/ERI (DJF) 1990-2008CWRF/ERI (MAM) 1990-2008CWRF/ERI (JJA) 1990-2008CWRF/ERI (SON) 1990-2008

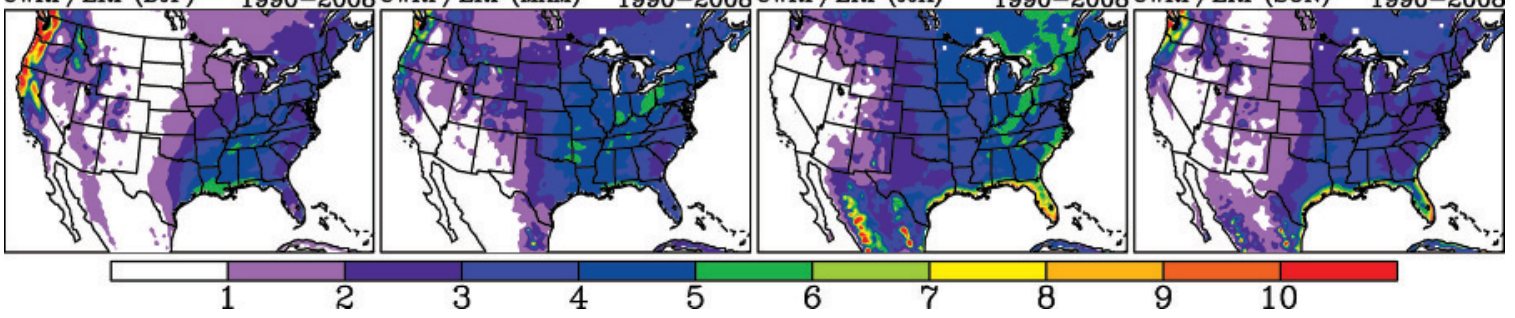

FIG. 3. The geographic distributions of seasonal (DJF, MAM, JJA, SON) mean precipitation ( $\mathrm{mm} \mathrm{day}^{-1}$ ) averaged during 1982-2004 as OBS and simulated by R-2, CMM5, WRFG, WRF, and CWRF. Also shown is the CWRF/ERI result averaged during 1990-2008, where observations have minor differences from the OBS. 
small, and the model precipitation is affected little by all choices of cumulus parameterization schemes. Sensitivity experiments show that the regional

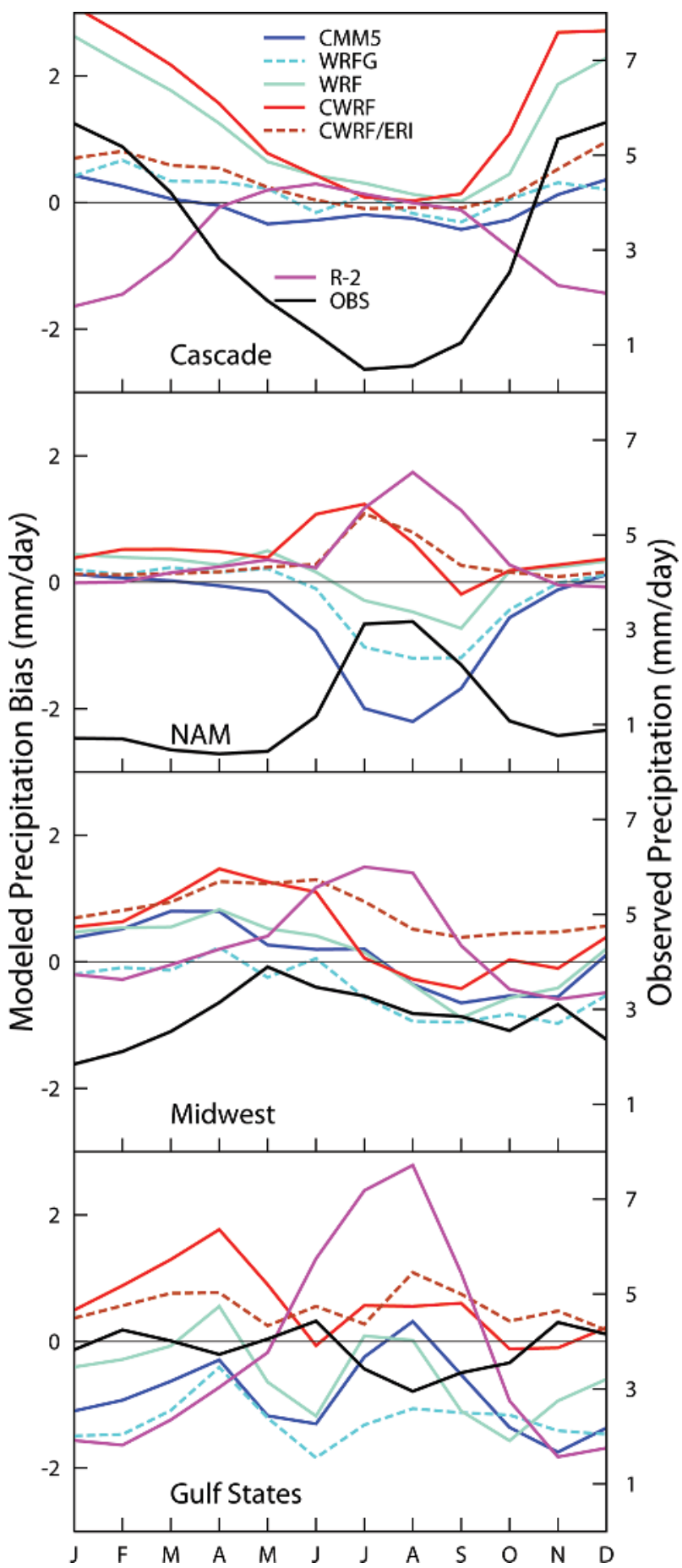

Fig. 4. The 1982-2004 mean annual cycles of precipitation biases ( $\mathrm{mm}$ day $^{-1}$, scale on left) simulated by the R-2, CMM5, WRFG, WRF, and CWRF along with observations ( $\mathrm{mm} \mathrm{day}$ day $^{-1}$, scale on right) as averaged over the four key regions. Also shown are the CWRF/ ERI biases averaged during 1990-2008. precipitation overestimation is systematic for all microphysics schemes available in CWRF or WRF. The reduced bias from WRF to WRFG likely results from the coarser resolution, which leads to weaker orographic lift and thus less precipitation. By this explanation, we speculate that CMM5 may produce weaker lift than CWRF due to, for example, stronger numerical damping. It is not clear what causes the overestimation increase from WRF to CWRF. In contrast, the CWRF/ERI integration mostly eliminates the overestimation, producing precipitation seasonal variations very close to observations in both phase and magnitude (Figs. 3 and 4). Therefore, the existence of large-scale forcing errors is probably the major cause for CWRF and WRF overestimation of the orographic precipitation when driven by the R-2 LBCs.

Over the Southwest, the summer rainfall maximum is caused by the NAM. The CMM5 basically fails to simulate the NAM rainfall pattern due to various factors discussed in Liang et al. (2004b). The WRF and WRFG results are improved somewhat, but there is still a general underestimation. Simulation of the NAM remains a challenging issue for both RCMs and GCMs (Liang et al. 2008a,b). Conversely, CWRF (also CWRF/ERI) generally captures the observed NAM rainfall characteristics, including the mean geographic distribution (Fig. 3), annual cycle (Fig. 4), and daily evolution (not shown). Note that the observational analysis makes no topographic adjustment over the NAM region and hence likely underestimates the actual peak rainfall amounts along the mountain ranges. Given this success, CWRF provides an excellent tool for future sensitivity studies to better understand the physical processes that govern NAM rainfall variability. For example, a sensitivity experiment for year 1993 indicates that the CWRF's successful simulation of the NAM rainfall variation is mainly attributed to its use of the ECP cumulus parameterization, with relatively small dependence on other driver schemes. In contrast, G3 (in WRF), GD (in WRFG), GR (in CMM5), BMJ, MIT, TDK, SAS, and NSAS all produce large summer deficit, while NKF and ZML yield large summer overestimation.

Over the Midwest, abundant precipitation is a critical element for the most productive agriculture in the world. The WRFG systematically underestimates the regional precipitation from July to December. It is a common difficulty for other RCMs (Takle et al. 1999; Mearns et al. 2012) to make an accurate simulation over this region, where rainfall results from multiscale circulations involving extratropical cyclones and the accompanying upper-level westerly jet 
but also regional phenomena, such mesoscale convective complexes and the nocturnal low-level southerly jet. In contrast, as with CMM5 (Liang et al. 2004b), CWRF reasonably well reproduces the regional precipitation distribution. The CWRF generates the most realistic precipitation in autumn through early winter, but there is some underestimation during summer and overestimation during spring. The WRF shares a similar performance with CWRF except for smaller excess in spring but a larger deficit from summer to autumn. Note that, in terms of absolute biases averaged over the year, WRF is slightly better than CWRF, comparing 0.49 to $0.61 \mathrm{~mm} \mathrm{day}^{-1}$. It is beyond the scope of this study to determine the causes for the seasonal contrast between the two models.

For the Gulf states, the rainfall results are mainly from convective processes associated with tropical disturbances (easterly waves, tropical cyclones) in the warm season and with extratropical cyclones associated with the southward advance of the upper-level jet stream in the cold season. The WRFG largely underestimates rainfall throughout the year, especially in summer through winter. Similar problems were identified in other RCMs (see Liang et al. 2004b). The CMM5 and WRF improve the result somewhat but still produce large deficits except in April, July, and August. In contrast, CWRF captures the general characteristics of the rainfall geographic distribution and seasonal variation, but it overestimates the amount by $10 \%-15 \%$. [On average over the year, CWRF absolute biases are very close to WRF, comparing 0.63 with $0.62 \mathrm{~mm}^{\text {day }}{ }^{-1}$.] In particular, CWRF simulates excessive rainfall over the southern Great Plains in spring and along the Gulf coast throughout the year. Sensitivity experiments show that these overestimations are mainly due to the CWRF use of the moisture convergence closure in the current ECP cumulus scheme, and that it can be reduced by refining the closure algorithm, for example, using the cloud work function tendency or imposing a certain perturbation to decrease the convective base mass flux.

Note that R-2 incorporates no direct precipitation measurements, such that its precipitation is a product generated by the global assimilation model in balance with the constraint of observed atmospheric circulation fields. Thus, the R-2 precipitation result provides a reference for the RCM downscaling skill enhancement due to its refined spatial resolution and improved physics representation. Clearly, R-2 cannot resolve the mesoscale orographic precipitation patterns west of the Rockies during winter, spring, and autumn, with large underestimations on the west slopes of all major mountain ranges and overestimations on the east slope of the Cascade Range. R-2 produces excessive summer rainfall over Mexico as well as the Gulf and eastern states but large dry winter biases over the Gulf states and Cascade Range. For all these regional features, the CWRF downscaling has significant skill enhancement over the driving R-2.

Figures 5 and 6 compare the corresponding biases (simulations minus observations) between the RCMs for surface air temperature and downwelling shortwave radiation flux, respectively. Four major conclusions can be drawn from the comparison. First, systematic warm biases exist across the Great Plains. This is evident even in WRF, which produces cold biases virtually everywhere else. CWRF experiments indicate that such warm biases are sensitive to the surface albedo parameterization and the vegetation distribution developed from the earlier MODIS and AVHRR products, respectively (Liang et al. 2005a,d). A revised albedo parameterization with a new vegetation distribution, both from the updated MODIS data, substantially reduces the biases, with general improvement over most of the domain. Second, cold biases occur over Mexico, especially for WRFG and WRF. They are coincident with the peak ranges of the Sierra Madres. Given the lack of direct measurements at high elevations over steep mountainous regions, the uncertainties in the CRU analysis without orographic adjustments are likely large. The CMM5 has small cold biases but is accompanied with large rainfall deficits. In contrast, CWRF temperature and rainfall biases are both relatively small and within the observational uncertainties. Third, shortwave radiation is substantially overestimated over most land areas by CMM5, WRFG, and WRF, especially in spring and summer with excesses of 30-60 $\mathrm{W} \mathrm{m}^{-2}$. The CWRF, however, produces a much more realistic simulation, mostly within $\pm 20 \mathrm{~W} \mathrm{~m}^{-2}$. Fourth, inconsistencies exist in biases among variables. For example, WRF has excessive shortwave radiation, counter to its notable cold biases. WRFG and CMM5 have similar radiation overestimations but smaller temperature biases; these model deficiencies seem disconnected. In contrast, the CWRF result is quite realistic for both radiation and temperature, where their biases are consistent with the intuitive physics expectation.

The CWRF incorporates aerosol radiative effects. The direct effect is calculated from MISR monthly climatological mean data of the angstrom exponent, total aerosol optical depth and single scattering albedo, along with the MODIS asymmetry factor. These data are linearly interpolated in both time and space for instantaneous radiation calculation at model 
grids. The indirect effect is based on Martin et al. (1994) through modification on cloud effective radius, whereas the impact on precipitation is deactivated. The lack of the aerosol effects in the other RCMs explains less than one-quarter of their differences from CWRF shown in Fig. 6. A sensitivity experiment for year 1993 indicates that the aerosol effects reduce surface shortwave radiation flux by $5-20 \mathrm{~W} \mathrm{~m}^{-2}$ in CWRF, with peaks during spring in response to maximum loadings. This reduction is more uniformly distributed in space and much smaller in magnitude than the CWRF differences from other RCMs. The more realistic CWRF simulation of radiation results mainly from a better cloud prediction, along with the improved surface albedo parameterization.

Note that the driving LBCs' uncertainties have profound effects on the RCM downscaling skill. The ERI large-scale forcings enable CWRF to reproduce the precipitation and temperature patterns more realistically than those driven by the R-2 LBCs. The
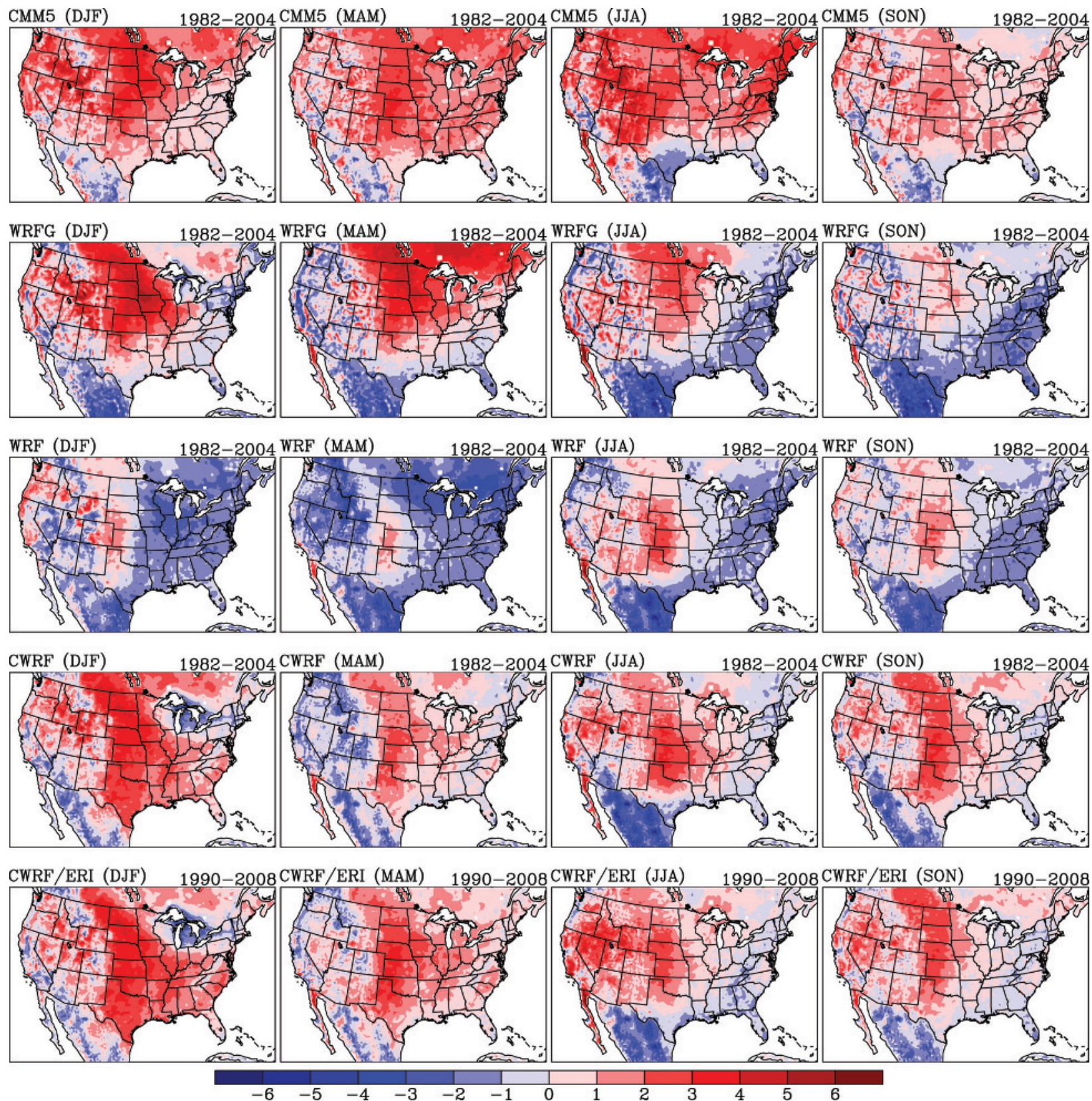

FIG. 5. The geographic distributions of seasonal (DJF, MAM, JJA, SON) mean surface air temperature ( ${ }^{\circ} \mathrm{C}$ ) biases (departures from observations) averaged during 1982-2004 as simulated by CMM5, WRFG, WRF, and CWRF. Also shown is the CWRF/ERI biases averaged during 1990-2008. 
improvements are most obvious for precipitation over the Cascade Range during winter and spring (as discussed earlier), the Southeast in spring, and the Southern Great Plains in autumn, as well for temperature with general bias reductions especially in summer and autumn. The large sensitivity to driving conditions cautions that any serious finetuning of the RCM physics schemes must be made in conjunction with a rigorous assessment of the LBCs' uncertainties. Nonetheless, the GSFC radiation, CSSP surface, and ECP cumulus schemes, newly developed in CWRF, have certain advantages over their counterparts, producing overall smaller climate biases and better temporal correspondences. Their consistent integration is the key reason for the notable improvement in the downscaling skill of CWRF over the typical WRF physics configuration and also the well-established CMM5 (Liang et al. 2004b).
CWRF PERFORMANCE ON INTERANNUAL VARIATION. Figure 7 compares seasonal spatial frequency distributions of pointwise correlation coefficients and rms errors of precipitation, surface air temperature, and downwelling shortwave radiation flux variations during 1982-2004 between observations and simulations by CWRF, WRF, WRFG, and CMM5. The statistics are based on monthly means for all land grids over the entire inner domain (excluding the buffer zones). As a general rule, the peak frequency occurring more to the right (left) indicates that the respective model simulation has more grids of higher correlations (smaller rms errors) with observations and hence is more realistic overall. The correlations measure the temporal correspondences, while the rms errors depict the magnitude differences between modeled and observed interannual variations. Clearly, WRFG's performance
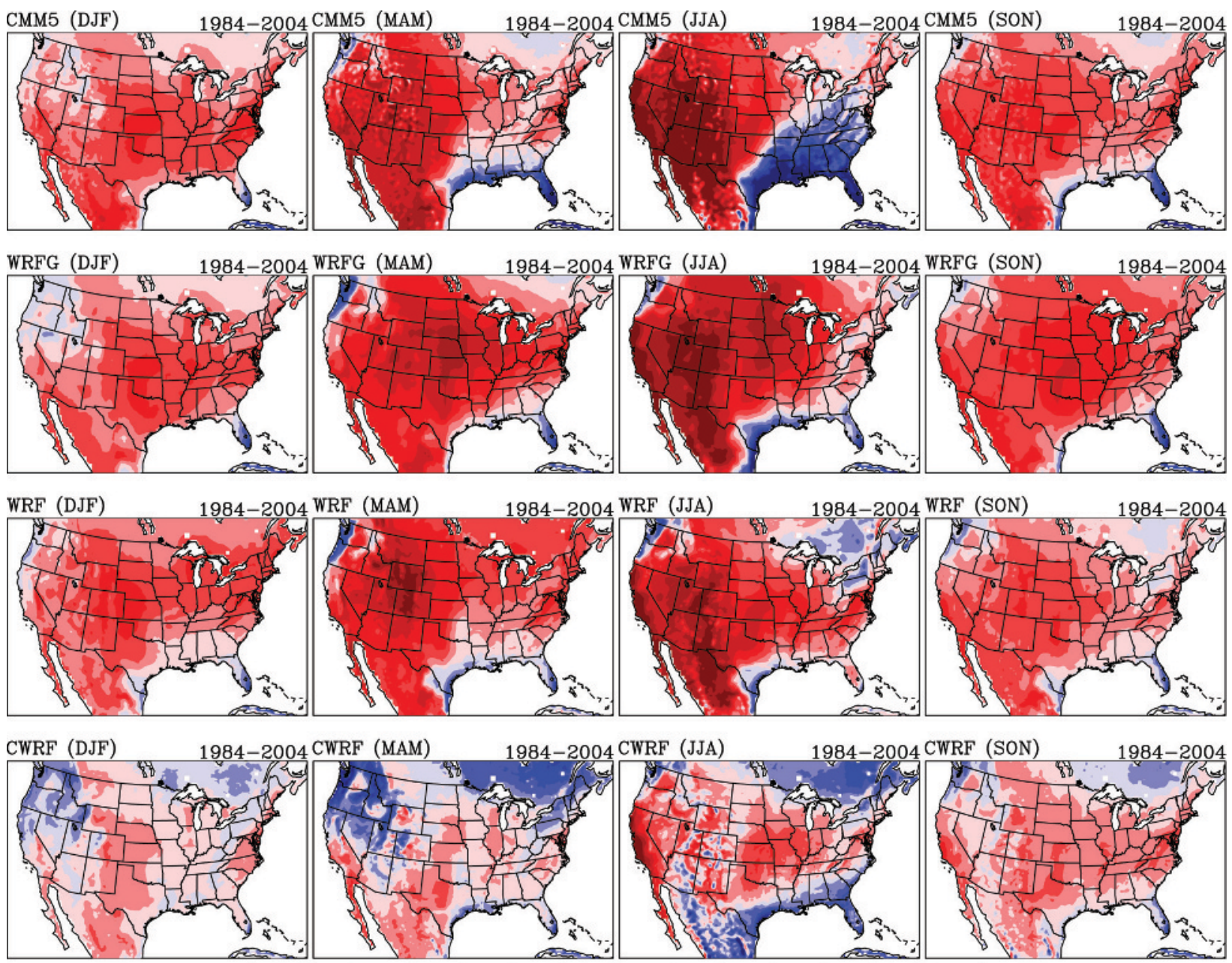

$\begin{array}{lllllllllllll}-60 & -50 & -40 & -30 & -20 & -10 & 0 & 10 & 20 & 30 & 40 & 50 & 60\end{array}$

FIG. 6. The geographic distributions of seasonal (DJF, MAM, JJA, SON) mean surface downwelling shortwave radiation flux $\left(\mathrm{W} \mathrm{m}^{-2}\right)$ biases (departures from observations) averaged during 1984-2004 as simulated by CMM5, WRFG, WRF, and CWRF. 
is the worst by both statistics in all seasons for all the three variables. This results partially from its use of a coarser horizontal resolution and a larger computational domain. For precipitation and temperature, the CWRF and WRF skills are comparable and slightly better than those of CMM5. By contrast,
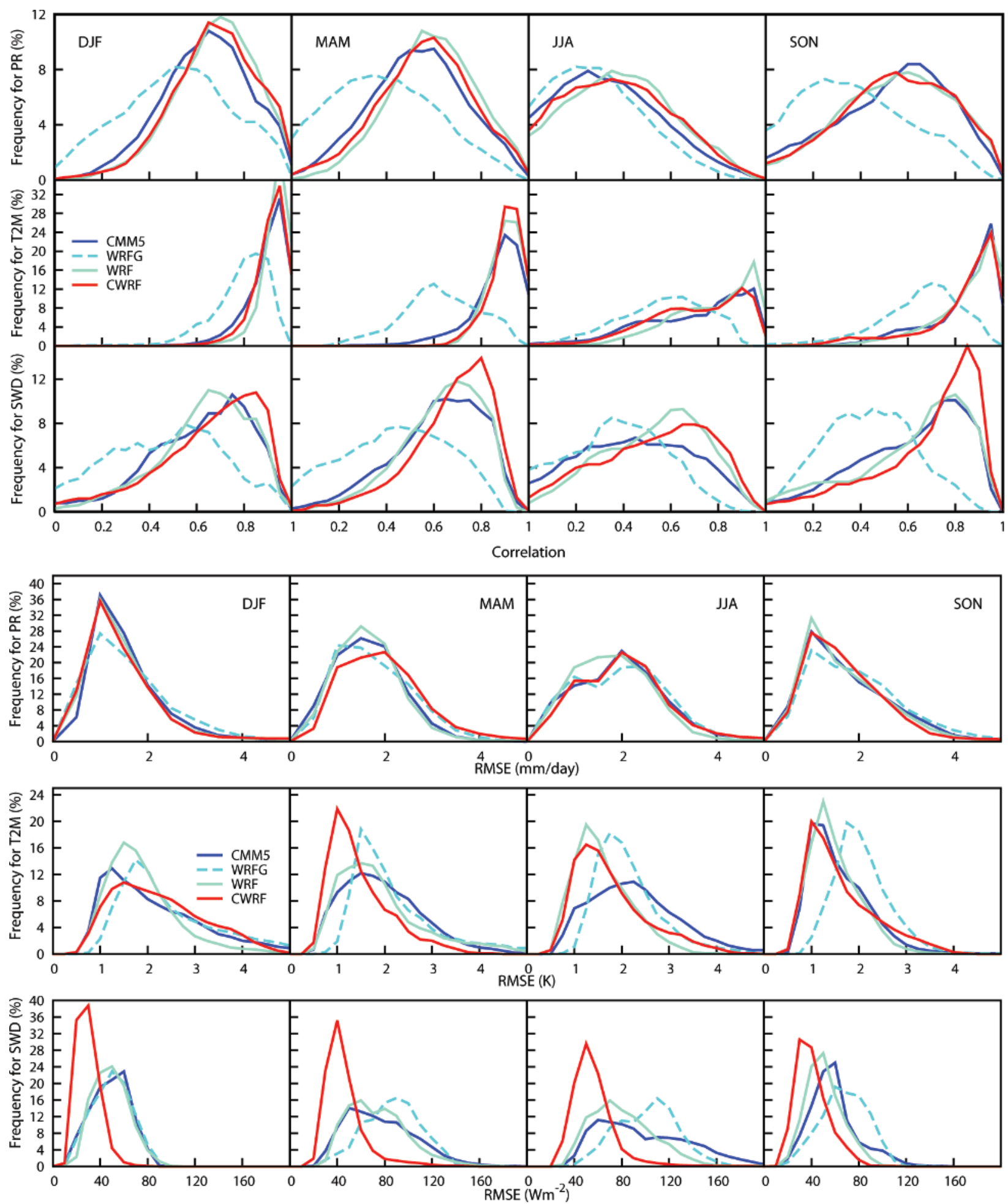

FIG. 7. Spatial frequency distributions of (top) correlations and (bottom) rms errors between simulated (CMM5, WRFG, WRF, CWRF) and observed monthly mean variations of PR ( $\mathrm{mm} \mathrm{day}^{-1}$ ), surface air temperature (T2M, $K)$, and surface downwelling shortwave radiation flux $\left(\mathrm{W} \mathrm{m}^{-2}\right)$ in the four seasons (DJF, MAM, JJA, SON) during 1982-2004 (1984-2004 for radiation). 
for radiation, CWRF exibits notable improvement to the others throughout the year, particularly as measured by rms errors.

Figure 8 compares, with observations, the CWRFand WRF-simulated annual cycles and the interannual variations of precipitation and soil moisture in the top 0.1-, 1-, and 2-m soil layers averaged over Illinois during 1984-2008. Clearly, the CWRF result is more realistic than that of WRF. For both annual cycle and interannual variation, correlation coefficients with observations are systematically higher as simulated by CWRF than by WRF. The enhancement is especially large for soil moisture, with correlation increases of $0.07-0.13$. For the annual cycle, WRF overestimates the amplitude, increasingly so toward deeper soil and doubled in the top $2 \mathrm{~m}$; but, its soil moisture is much drier than observations from summer to autumn (worst) to winter, and is associated with precipitation deficits. In contrast, the CWRF result is comparable to observations, with some overestimation in spring that is accompanied by precipitation excesses. For the interannual variation, CWRF tracks observations very well, with correlations of $0.74-0.78$, whereas WRF overestimates the variability along with systematic drier conditions. The standard deviation ratio (simulated to observed) for the top 1-m soil moisture is 1.52 for WRF and 0.91 for CWRF, respectively, and for the top 2-m it is 1.88 and 1.23 , respectively. Thus, CWRF generates not only more realistic phase (higher correlations) but also better amplitude (deviation ratios closer to 1) of the soil moisture seasonal-interannual variations throughout the root zone than WRF. This contrast mainly arises from the advanced representation of the terrestrial hydrology in CWRF using the CSSP surface scheme as compared to the WRF use of the Noah scheme. As demonstrated by Yuan and Liang (2011a) and the more recent comparison of offline integrations driven by observational reanalysis data, the CSSP has clear advantages in modeling the U.S. terrestrial hydrology (soil moisture, runoff) over its root models and the Noah scheme.

Figure 9 compares, with observations, the CWRF and WRF geographic distributions of interannual correlation coefficients of monthly mean anomalies (with the annual cycle removed) between surface air temperature and downwelling shortwave radiation during 1984-2004. Assuming monthly independence,
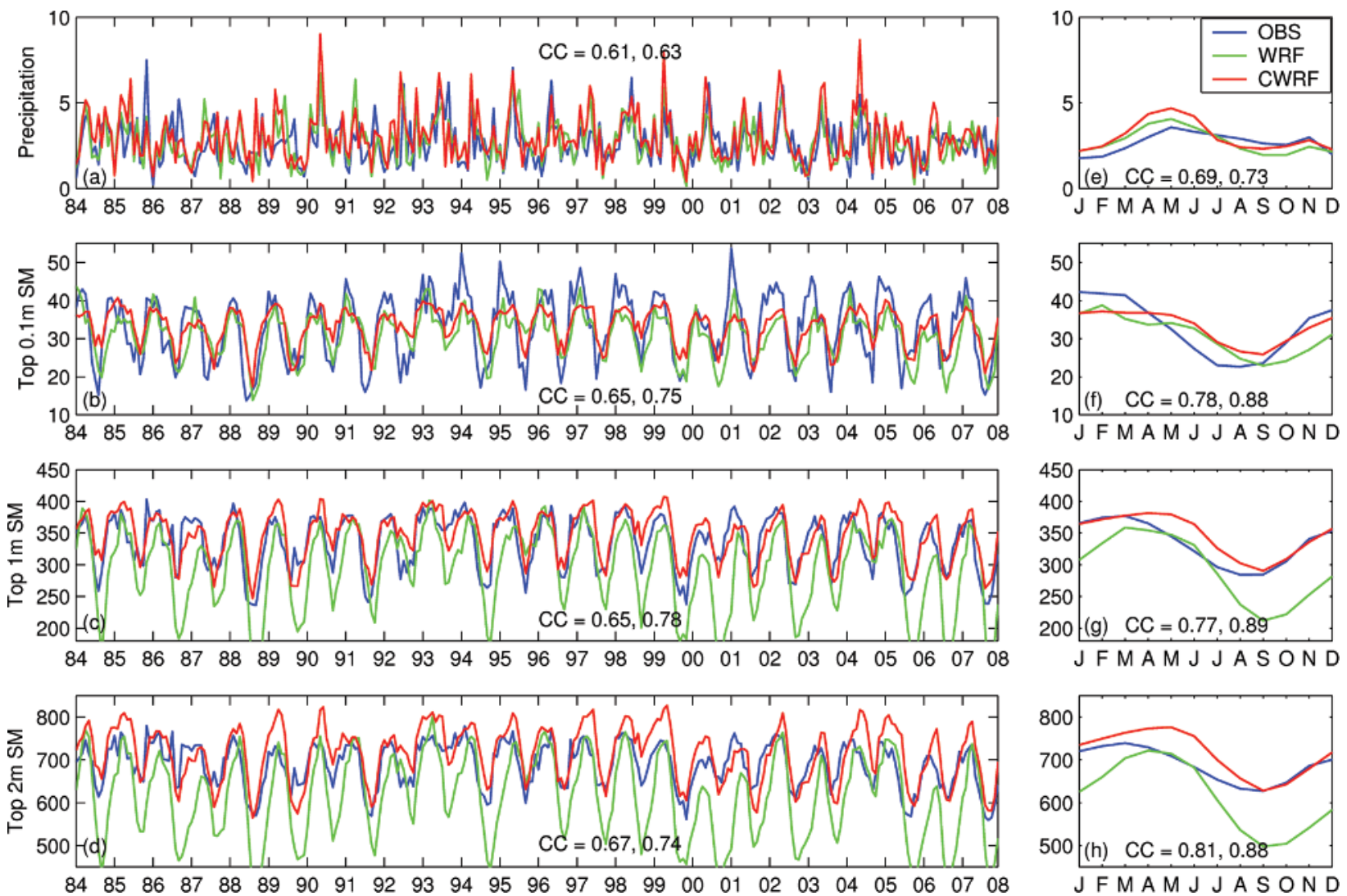

FIG. 8. Monthly mean precipitation $\left(\mathrm{mm} \mathrm{day}^{-1}\right)$ and soil moisture $(\mathrm{mm})$ for the top 0.I-, I-, and 2-m soil layers averaged over Illinois as observed and simulated by the CWRF and WRF. Shown are (left) interannual variations, (right) annual cycles, and CC of simulations (WRF then CWRF) with observations. 
correlation magnitudes greater than 0.248 are statistically significant at the $95 \%$ level. Observed surface temperature and radiation are positively correlated along the Great Plains throughout the year, most significantly during summer, when it extends to almost the entire domain except the southwestern United States. Positive (albeit weaker) correlations are also observed in spring and autumn over broad regions, including the western United States. For these regions, surface temperature changes largely in response to solar radiation forcing. Negative correlations are observed in winter over the northwestern and centralnortheastern United States and adjacent Canadian regions, and in autumn over the southeastern United States. These negative relationships likely result from the snow-albedo feedback (warmer temperatures causing more snowfall, reflecting more radiation) in northern latitudes and from the convection-cloud feedback (warmer temperatures causing more convective cloud, reflecting more radiation) in low latitudes. The CWRF realistically captures these observed patterns but overestimates the strength of winter
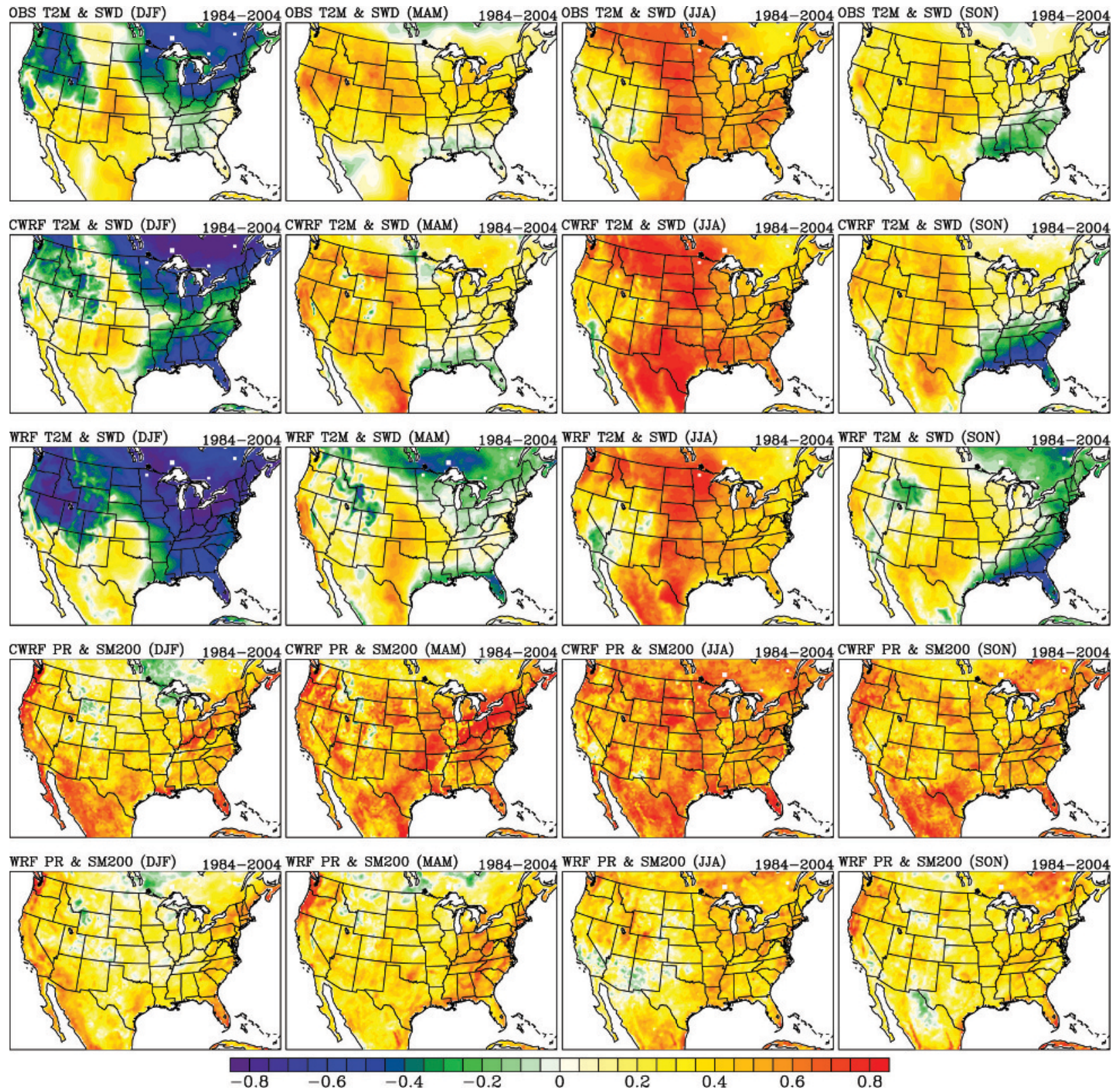

FIG. 9. The geographic distributions of seasonal (DJF, MAM, JJA, SON) averaged interannual correlation coefficients of monthly mean anomalies (with the annual cycle removed) during 1984-2004 between surface air temperature (T2M) and SWD OBS and simulated by CWRF and WRF, as well as those simulated between PR and SM200. 
negative and summer positive correlations. The WRF simulation is overall less realistic, where it overestimates negative correlations over more extensive regions in both winter and autumn, and even during spring, when they are absent in both observations and the CWRF simulation.

Figure 9 also compares CWRF- and WRFsimulated correlations between precipitation and the top 2-m soil moisture anomalies during 1984-2004. Both models produce mainly positive correlations, that is, more precipitation is associated with wetter soil moisture. Significant correlations are generated by CWRF in winter, spring, summer, and autumn over $61 \%, 78 \%, 94 \%$, and $87 \%$ of land grids, respectively, compared to $46 \%, 60 \%, 72 \%$, and $61 \%$ of land grids, respectively, by WRF. In particular, CWRF simulates large correlations in spring and summer over Mexico and the Great Plains, where strong landatmosphere coupling has been identified (Koster et al. 2004). The WRF, however, generates rather weak correlations. Such relationships, having important consequences on regional hydrology and climate prediction, require verification with future available observations for soil moisture distributions.

\section{CWRF PHYSICS ENSEMBLE PREDIC- TION-A CAPABILITY TEST. The CWRF} incorporates a massive suite of alternative numerical schemes for microphysics, convection, cloud, aerosol, radiation, surface, turbulence, and transport processes, all of which are fully coupled with nonlinear interactions. The CWRF downscaling can significantly reduce the biases of the driving global reanalyses (e.g., Figs. 3 and 4) or climate models (e.g., Yuan and Liang 2011b). The skill enhancement, however, is sensitive to model physics configurations, and no single combination of the available schemes can adequately simulate all key aspects of the observed climate system. Various physics schemes work better in different regions with distinct climate regimes. Consensus predictions based on an ensemble of multiple physics configurations may offer significant skill enhancement (Liang et al. 2007; Zeng et al. 2008a; Liu et al. 2009). A preliminary test demonstrating the capability of the CWRF physics ensemble to improve precipitation prediction at regional-local scales was conducted.

The test uses a limited subset of the CWRF full ensemble, focusing on the control configuration (same as used in the 1979-2009 simulation presented in the previous sections) and all major alternative schemes across each physics driver, altered one at a time; a total of 26 configurations were modeled.
Table S1 lists, for each driver, these alternative schemes and their key references (see supplementary material for exact citations). Each simulation is driven by the R-2 LBCs and integrated from 1 November 1992 to 31 December 1993, with the initial two months used as a model spinup. During the 1993 summer, record flooding occurred in the Mississippi River basin. This extreme event has been associated with physical mechanisms at both the planetary and regional-local scales (e.g., Kunkel et al. 1994) and thus is an ideal case for evaluation of the RCMs' performance (Liang et al. 2001).

Figure 10 illustrates the spatial frequency distributions of pointwise correlation coefficients and $\mathrm{rms}$ errors of daily mean rainfall variations between observations and simulations by CWRF for the 26 physics configurations. The statistics are shown in five color groups, each containing the tested schemes of a specific physics driver. Shown also are the ensemble results as the averages of all runs with either equal or optimal weights. The latter is computed based on the local minimization of rms errors in an entire season, and the skill score depicts the upper limit of daily rainfall predictability that can be achieved from the best optimization of the ensemble. Clearly, the equal-weight ensemble average of alternative physics configurations substantially increases the predictive skill over all individual schemes, with more frequent occurrences of higher correlation coefficients and smaller rms errors. The skill enhancement is most pronounced in summer, followed by autumn and spring, but rather weak in winter.

The CWRF overall performance is very similar among all the individual configurations except for those using CSU, GFDL, MIT and ZML cumulus schemes. These schemes happen to be widely used in the latest global GCMs. They underestimate total precipitation and have poorer daily correspondence with observations, leading to systematically larger rms errors and lower correlations than the ECP, BMJ and NKF schemes typically used in mesoscale RCMs. In contrast, their removal actually reduces the ensemble average skill. Hence, these schemes contain certain regional signals that are complementary to others.

The ensemble average using the localized optimal weights has predictive skill significantly higher than that using the equal weight as well as the individuals throughout the entire year. Thus, there exists substantial room to further enhance that skill through intelligent optimization. This optimized physics ensemble downscaling approach provides a promising pathway for skill enhancement of predicting weather and climate, especially precipitation, at regional-local 


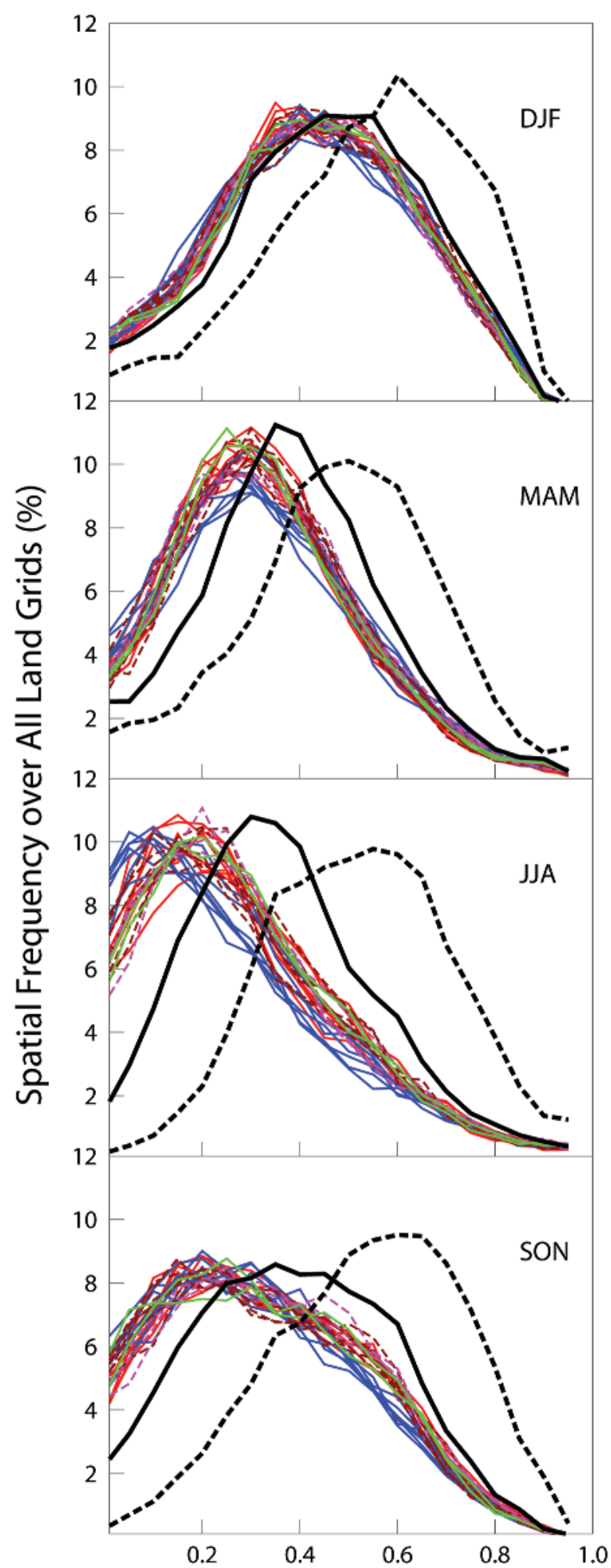

Correlation Coefficient

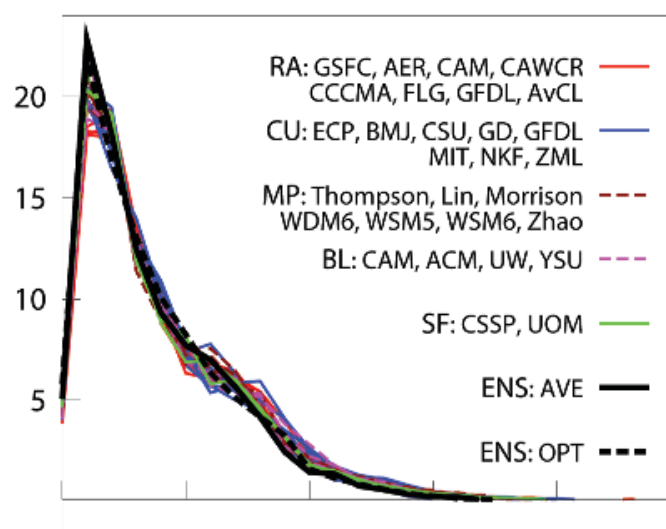

20
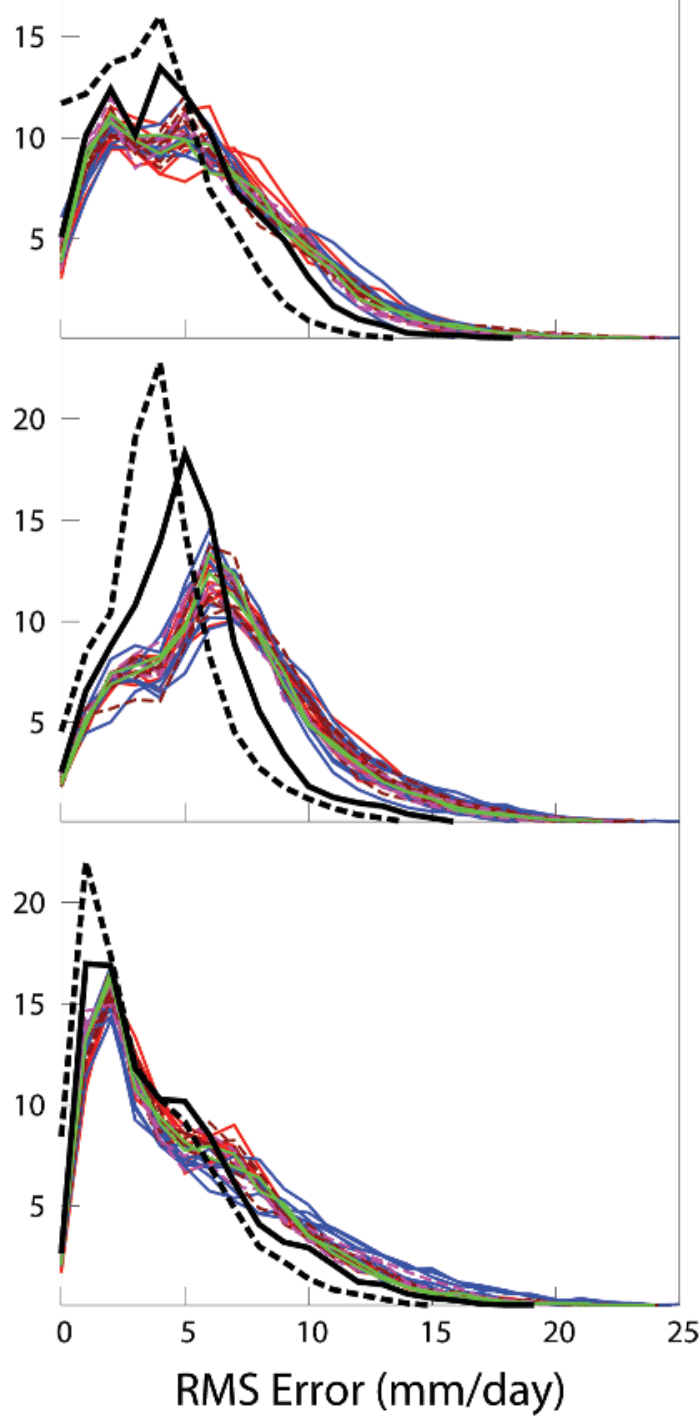

FIG. 10. Spatial frequency distributions of (left) correlations and (right) rms errors between CWRF and OBS daily mean rainfall variations in the four seasons (DJF, MAM, JJA, SON) of 1993 for all the model physics configurations listed in Table SI. Each line depicts a specific configuration in groups of the five key physical processes (color). The ENS is the average of all runs with AVE or OPT weights, shown as a black solid or dashed line, respectively. 
scales (Zeng et al. 2008a; Yuan and Liang 2011b; Yuan et al. 2012). We intend to explore various posterior optimization methods, including Liang et al. (2007), Kug et al. (2008), and Lee et al. (2011), to maximize the ensemble predictive skill. These methods are posterior because they are based on postsimulation composite analyses of multiple model outputs rather than improving a specific model physics configuration or a particular parameterization. Given that an individual scheme's performance is regime dependent, a better result is achievable through dynamic optimization of an overall predictive system. A good example of this concept is the ECP cumulus scheme modified from Grell and Dévényi (2002) that utilizes a suite of alternative closure assumptions. In principle, this approach applies an ensemble of cumulus parameterizations at every time step and at each grid point, and then feeds back the average of all solutions to the predictive system. The current ECP implements the moisture convergence plus cloud work function closures with an equal weight over land and the cloud work function closure only over ocean, and then feeds back the ensemble result to interact with the other processes of CWRF. Such a dynamic approach can be expanded to construct an optimized CWRF predictive system that consists of an ensemble of multiple alternative schemes for each physics driver with appropriate regime-specific weights. These weights can be derived from retrospective predictions made with individual schemes and functional relationships established with static (geographic distribution, such as land vs ocean) or dynamic (spatiotemporal distribution, such as model-resolvable variables) quantities. The derivation will involve forecast error analysis and inverse modeling to minimize the model-toobservation differences. In this regard, advanced data assimilation techniques, such as LETKF (Hunt et al. 2007), will play a critical role.

SUMMARY AND DISCUSSION. The goal of the CWRF development has been to achieve a regional modeling system that can be applied seamlessly to weather forecast and climate prediction as well as to climate impacts assessment at regional-local scales. The CWRF has been built on three main principles, emphasizing 1) an extension of WRF to capitalize on the broad community efforts for all weather forecast functionalities while enhancing credible climate prediction capabilities; 2) a capability to use a grand ensemble of alternative schemes for key physical processes and their interactions to improve predictive skills through optimization against observations while providing robust uncertainty estimates; and 3) a service capability to provide impact-relevant information, including terrestrial hydrology, coastal ocean, crop growth, ecosystem, air quality, and water quality. The resulting CWRF is the state-of-the-science model that incorporates a comprehensive collection of interactive physics configurations fully exchangeable and capable of ensemble prediction and system optimization for general applications at a wide range of temporal and spatial scales.

The CWRF performance was evaluated over land areas of the contiguous United States plus southern Canada and northern Mexico using a continuous integration driven by R-2 during 1979-2009 and compared with those of CMM5 (Liang et al. 2004b) and the original WRF, and also a similar run of WRFG based on the earlier WRF version 2 over an extended domain of relatively coarse grid spacing (Leung et al. 2011). The CWRF's control physics configuration, not available in WRF, consists of the GSFC radiation, CSSP-landplus-UOM-ocean surface, CAM-eddy-plus-OROorography PBL, ECP-deep-plus-UW-shallow cumulus, and GSFC GCE microphysics schemes. Compared to the other RCMs, CWRF more realistically reproduces the principal characteristics of the observed geographic distributions, seasonal-interannual variations, and coupled relationships among key variables, including surface air temperature, surface downwelling shortwave radiation flux, and Illinois soil moisture. However, accurate simulation of precipitation in all seasons and regions remains a challenge for all of the tested models. Further studies will evaluate other aspects of the model performance, including precipitation diurnal cycle, frequency distribution and extreme events, surface wind, terrestrial hydrology, energy partitioning, as well as responses to external (natural or anthropogenic) forcing and contrasts between land and ocean.

A preliminary test demonstrated the capability of a physics ensemble approach to improve precipitation prediction at regional-local scales. It involved a total of 26 selected key physics configurations, each with a simulation for year 1993, when the record summer flood occurred over the U.S. Midwest. These configurations represent a small subset (from a system of $10^{24}$ choices), focusing on only the control configuration and major alternative schemes, altered one at a time, across each physics driver of radiation, surface, PBL, cumulus, and microphysics processes. The ensemble average of these configurations using an equal weight substantially increases the predictive skill of daily rainfall variations over all individuals. The skill enhancement, with increased occurrence of higher correlation coefficients and smaller rms 
errors, is most pronounced during summer, followed by autumn and spring, but rather weak in winter. There exists, however, substantial room to further enhance that skill through intelligent optimization of the ensemble, especially for precipitation.

The advances in both physics formulations and predictive skills documented above justify the initial release of CWRF for community use (http://cwrf.umd .edu). We plan to update CWRF following future new WRF releases with identical model version numbers. Because of the lack of funding for model development and user support, these updates are expected to be less frequent than those for WRF. It is hoped that CWRF, with a comprehensive but expandable ensemble of alternative physics schemes, will facilitate fundamental progress on quantitative understanding and probabilistic prediction of climate variability and change at regional-local scales. A critical need for cost-effective modeling is to define a viable subset of the ensemble with a computationally feasible and manageable size that best captures the full range of observed climate processes. An initial but substantial reduction in the choices of CWRF configurations for consideration can be made through basic knowledge of the prevailing physical processes that dominate regional climate variations over the domain of interest. Further reduction can be obtained via CWRF sensitivity experiments for certain weather or climate systems typical of the region. Intelligent optimization against observations can then be sought to create the optimized physics ensemble that incorporates statistical or dynamic weights to account for the relative contributions of individual members depending on climate regimes. This will improve the fidelity of climate change predictions and their utility for impacts assessment and strategic planning. The developed ensemble of alternative physics schemes in CWRF can be applied to other regional as well as global climate models at similar mesoscale resolutions. Its general application, however, requires accurate specification of the most comprehensive surface boundary conditions, some of which are not readily available. This requirement arises from the necessary coupling with the advanced CSSP that significantly improves the simulation of terrestrial hydrology processes. The actual performance of the ensemble and its individual members also will inevitably depend on model resolution. These issues, both scientific and technical, will be the focus of future studies.

ACKNOWLEDGMENTS. We acknowledge the WRF developers for the integrated effort making this model available as the excellent base from which CWRF has been developed; the PRISM group at Oregon State University for precipitation data with topographic correction; Ruby Leung for the WRFG simulation; and Arthur Samel, Gary Lackmann (editor), and two anonymous reviewers for their constructive comments and suggestions for improving the manuscript. This research was supported by the state of Illinois through the CAQIMS modeling program, the NOAA Education Partnership Program (EPP) subaward COM Howard 631017 and Climate Prediction Program for the Americas (CPPA) Grants NA08OAR4310575 and NA08OAR4310875, the EPA Science to Achieve Results (STAR) Grants RD-83337302 and RD-83418902, the DOE Office of Biological and Environmental Research (BER) Grant DE-SC0001683, the Colorado State University UV-B Monitoring and Research Program subaward USDACSREES-2009-34263-19774 (G-1449-1), the NASA Grant NNX08AL94G, the National Science Foundation (NSF) Grants ATM 06-28687 and DMS 07-24752, the China National Basic Research Program Grant 2010CB951603, and the Shanghai Science and Technology Support Program Grant 10DZ0581600. The model simulations were conducted at the DOE/NERSC, NOAA/ESRL, and UIUC/ NCSA supercomputing facilities. The views expressed are those of the authors and do not necessarily reflect those of the sponsoring agencies.

\section{REFERENCES}

Angevine, W. M., H. Klein Baltink, and F. C. Bosveld, 2001: Observations of the morning transition of the convective boundary layer. Bound.-Layer Meteor., 101, 209-227.

Anthes, R. A., E.-Y. Hsie, and Y.-H. Kuo, 1987: Description of the Penn State/NCAR Mesoscale Model version 4 (MM4). NCAR Tech. Note NCAR/TN282+STR, 66 pp.

Arakawa, A., 2004: The cumulus parameterization problem: Past, present, and future. J. Climate, 17, 2493-2525.

Awan, N. K., H. Truhetz, and A. Gobiet, 2011: Parameterization-induced error characteristics of MM5 and WRF operated in climate mode over the Alpine region: An ensemble-based analysis. J. Climate, 24, 3107-3123.

Bader, D. C., C. Covey, W. J. Gutowski Jr., I. M. Held, K. E. Kunkel, R. L. Miller, R. T. Tokmakian, and M. H. Zhang, 2008: Climate Models: An Assessment of Strengths and Limitations. U.S. Climate Change Science Program Synthesis and Assessment Product 3.1, Department of Energy, Office of Biological and Environmental Research, $124 \mathrm{pp}$.

Bukovsky, M. S., and D. J. Karoly, 2009: Precipitation simulations using WRF as a nested regional climate model. J. Appl. Meteor. Climatol., 48, 2152-2159. 
Caldwell, P., H.-N. S. Chin, D. C. Bader, and G. Bala, 2009: Evaluation of a WRF dynamical downscaling simulation over California. Climatic Change, 95, 499-521, doi:10.1007/s10584-009-9583-5.

Chen, F., and J. Duhia, 2001: Coupling an advanced land surface-hydrology model with the Penn State-NCAR MM5 modeling system. Part I: Model implementation and sensitivity, Mon. Wea. Rev., 129, 569-585.

Chen, M., W. Shi, P. Xie, V. B. S. Silva, V. E. Kousky, R. W. Higgins, and J. E. Janowiak, 2008: Assessing objective techniques for gauge-based analyses of global daily precipitation. J. Geophys. Res., 113, D04110, doi:10.1029/2007JD009132.

Chin, H.-N. S., P. M. Caldwell, and D. C. Bader, 2010: Preliminary study of California wintertime model wet bias. Mon. Wea. Rev., 138, 3356-3571.

Choi, H. I., 2006: 3-D volume averaged soil-moisture transport model: A scalable scheme for representing subgrid topographic control in land-atmosphere interactions. Ph.D. dissertation, University of Illinois at Urbana-Champaign, 189 pp.

— , and X.-Z. Liang, 2010: Improved terrestrial hydrologic representation in mesoscale land surface models. J. Hydrometeor., 11, 797-809.

—, P. Kumar, and X.-Z. Liang, 2007: Threedimensional volume-averaged soil moisture transport model with a scalable parameterization of subgrid topographic variability. Water Resour. Res., 43, W04414, doi:10.1029/2006WR005134.

Chou, M.-D., and M. J. Suarez, 1999: A solar radiation parameterization for atmospheric studies. Technical Report Series on Global Modeling and Data Assimilation, Vol. 15, NASA/Goddard Space Flight Center, $42 \mathrm{pp}$.

— $-\longrightarrow$, X.-Z. Liang, and M. M.-H. Yan, 2001: A thermal infrared radiation parameterization for atmospheric studies. Technical Report Series on Global Modeling and Data Assimilation, Vol. 19, NASA/ Goddard Space Flight Center, 56 pp.

Christensen, J. H., and Coauthors, 2007: Regional climate projections. Climate Change 2007: The Physical Science Basis, S. Solomon et al., Eds., Cambridge University Press, 847-940.

Collins, W. D., P. J. Rasch, B. A. Boville, J. J. Hack, J. R. McCaa, D. L. Williamson, J. T. Kiehl, B. Briegleb, C. Bitz, S.-J. Lin, M. Zhang, and Y. Dai, 2004: Description of the NCAR Community Atmosphere Model (CAM3). NCAR Tech. Rep. NCAR/TN-464+STR, 226 pp.

Crétat, J., B. Pohl, Y. Richard, and P. Drobinski, 2012: Uncertainties in simulating regional climate of southern Africa: Sensitivity to physical parameterizations using WRF. Climate Dyn., 38, 613-634, doi:10.1007/s00382-011-1055-8.
Daly, C., M. Halbleib, J. I. Smith, W. P. Gibson, M. K. Doggett, G. H. Taylor, J. Curtis, and P. A. Pasteris, 2008: Physiographically-sensitive mapping of temperature and precipitation across the conterminous United States. Int. J. Climatol., 28, 2031-2064.

Druyan, L. M., M. Fulakeza, P. Lonergan, and E. Noble, 2009: Regional climate model simulation of the AMMA Special Observing Period \#3 and the pre-Helene easterly wave. Meteor. Atmos. Phys., 105, 191-210, doi:10.1007/s00703-009-0044-5.

Dudek, M. P., X.-Z. Liang, and W.-C. Wang, 1996: A regional climate model study of the scale dependence of cloud-radiation interactions. J. Climate, 9, 1221-1234.

Dudhia, J., D. Gill, K. Manning, W. Wang, and C. Bruyere, 2005: PSU/NCAR mesoscale modeling system tutorial class notes and user's guide (MM5 modeling system version 3). NCAR. [Available online at www.mmm .ucar.edu/mm5/documents/tutorial-v3-notes.html.]

Ek, M., K. E. Mitchell, Y. Lin, E. Rogers, P. Grunmann, V. Koren, G. Gayno, and J. D. Tarpley, 2003: Implementation of Noah land surface model advances in the National Centers for Environmental Prediction operational mesoscale Eta Model. J. Geophys. Res., 108, 8851, doi:10.1029/2002JD003296.

Evans, J. P., and M. F. McCabe, 2010: Regional climate simulation over Australia's Murray-Darling basin: A multitemporal assessment. J. Geophys. Res., 115, D14114, doi:10.1029/2010JD013816.

Flaounas, E., S. Bastin, and S. Janicot, 2011: Regional climate modelling of the 2006 West African monsoon: Sensitivity to convection and planetary boundary layer parameterisation using WRF. Climate Dyn., 36, 1083-1105.

Fowler, H. J., S. Blenkinshop, and C. Tebaldi, 2007: Linking climate change modelling to impacts studies: Recent advances in downscaling techniques for hydrological modelling. Int. J. Climatol., 27, 1547-1578.

Gallus, W. A., Jr., and J. F. Bresch, 2006: Comparison of impacts of WRF dynamic core, physics package, and initial conditions on warm season rainfall forecasts. Mon. Wea. Rev., 134, 2632-2641.

Giorgi, F., 2006: Regional climate modeling: Status and perspectives. J. Phys. IV, 139, 101-118.

— the sensitivity of simulated precipitation to model resolution and its implications for climate studies. Mon. Wea. Rev., 124, 148-166.

— section: Regional climate modeling revisited. J. Geophys. Res., 104 (D6), 6335-6352.

— , and Coauthors, 2001: Regional climate information - Evaluation and projections. Climate Change 
2001: The Scientific Basis, J. T. Houghton et al., Eds., Cambridge University Press, 583-638.

Gleckler, P. J., K. E. Taylor, and C. Doutriaux, 2008: Performance metrics for climate models. J. Geophys. Res., 113, D06104, doi:10.1029/2007JD008972.

Grell, G. A., and D. Dévényi, 2002: A generalized approach to parameterizing convection combining ensemble and data assimilation techniques. Geophys. Res. Lett., 29, 1693, doi:10.1029/2002GL015311.

— J J. Dudhia, and D. R. Stauffer, 1994: A description of the fifth-generation Penn State/NCAR Mesoscale Model (MM5). NCAR Tech. Note NCAR/TN398+STR, $121 \mathrm{pp}$.

Hack, J., B. Boville, B. Briegleb, J. Kiehl, and D. Williamson, 1993: Description of the NCAR Community Climate Model (CCM2). UCAR Tech. Rep. NCAR/TN-382+STR, 108 pp. [Available online at http://nldr.library.ucar.edu/repository/collections /TECH-NOTE-000-000-000-193.]

—, J. M. Caron, G. Danabasoglu, K. W. Oleson, C. Bitz, and J. E. Truesdale, 2006: CCSM-CAM3 climate simulation sensitivity to changes in horizontal resolution. J. Climate, 19, 2267-2289.

Heikkilä, U., A. Sandvik, and A. Sorteberg, 2011: Dynamical downscaling of ERA-40 in complex terrain using the WRF regional climate model. Climate Dyn., 37, 1551-1564, doi:10.1007/s00382-010-0928-6.

Hines, K. M., D. H. Bromwich, L.-S. Bai, M. Barlage, and A. G. Slater, 2011: Development and testing of polar WRF. Part III: Arctic land. J. Climate, 24, 26-48.

Holtslag, A. A. M., and B. A. Boville, 1993: Local versus nonlocal boundary-layer diffusion in a global climate model. J. Climate, 6, 1825-1842.

Hong, S.-Y., and H.-L. Pan, 1996: Nonlocal boundary layer vertical diffusion in a medium-range forecast model. Mon. Wea. Rev., 124, 2322-2339.

—-, Y. Noh, and J. Dudhia, 2006: A New Vertical Diffusion Package with an Explicit Treatment of Entrainment Processes. Mon. Wea. Rev., 134, 2318-2341, doi:10.1175/MWR3199.1.

Huang, H.-C., X.-Z. Liang, K. E. Kunkel, M. Caughey, and A. Williams, 2007: Seasonal simulation of tropospheric ozone over the midwestern and northeastern United States: An application of a coupled regional climate and air quality modeling system. J. Appl. Meteor. Climatol., 46, 945-960.

Hunt, B. R., E. J. Kostelich, and I. Szunyogh, 2007: Efficient data assimilation for spatiotemporal chaos: A local ensemble transform Kalman filter. Physica $D$, 230, 112-126.

Jankov, I., W. A. Gallus Jr., M. Segal, B. Shaw, and S. E. Koch, 2005: The impact of different WRF model physical parameterizations and their interactions on warm season MCS rainfall. Wea. Forecasting, 20, 1048-1060.

Jung, J.-H., and A. Arakawa, 2004: The resolution dependence of model physics: Illustrations from nonhydrostatic model experiments. J. Atmos. Sci., 61, 88-102.

Kanamitsu, M., W. Ebisuzaki, J. Woollen, S.-K. Yang, J. J. Hnilo, M. Fiorino, and G. L. Potter, 2002: The NCEP-DOE AMIP-II Reanalysis (R-2). Bull. Amer. Meteor. Soc., 83, 1631-1643.

Kiehl, J. T., and D. L. Williamson, 1991: Dependence of cloud amount on horizontal resolution in the National Center for Atmospheric Research Community Climate Model. J. Geophys. Res., 96, 10955-10980.

Kirtman, B. P., and D. Min, 2009: Multimodel ensemble ENSO prediction with CCSM and CFS. Mon. Wea. Rev., 137, 2908-2930.

Koster, R. D., and Coauthors, 2004: Regions of strong coupling between soil moisture and precipitation. Science, 305, 1138-1140.

Krishnamurti, T. N., C. M. Kishtawal, Z. Zhang, T. Larow, D. Bachiochi, E. Williford, S. Gadgil, and S. Surendran, 2000: Multimodel ensemble forecasts for weather and seasonal climate. J. Climate, 13, 4196-4216.

Kug, J.-S., J.-Y. Lee, I.-S. Kang, B. Wang, and C. K. Park, 2008: Optimal multi-model ensemble method in seasonal climate prediction. Asia-Pac. J. Atmos. Sci., 44, 259-267.

Kunkel, K. E., S. A. Changnon, and J. R. Angel, 1994: Climatic aspects of the 1993 upper Mississippi basin flood. Bull. Amer. Meteor. Soc., 75, 811-822.

Lee, D. Y., K. Ashok, and J.-B. Ahn, 2011: Toward enhancement of prediction skills of multimodel ensemble seasonal prediction: A climate filter concept. J. Geophys. Res., 116, D06116, doi:10.1029/2010JD014610.

Leung, L. R., and Y. Qian, 2009: Atmospheric rivers induced heavy precipitation and flooding in the western U.S. simulated by the WRF regional climate model. Geophys. Res. Lett., 36, L03820, doi:10.1029/2008GL036445.

—, L. O. Mearns, F. Giorgi, and R. L. Wilby, 2003: Regional climate research: Needs and opportunities. Bull. Amer. Meteor. Soc., 84, 89-95.

- J. Correia, and Y. Qian, 2011: An overview of the NARCCAP WRF simulations. 2011 Users' Meeting, Boulder, CO, NARCCAP. [Available online at http:// narccap.ucar.edu/doc/presentations/leung-wrf_ overview_for_3rd_narccap_users_meeting.pdf.]

Liang, X.-Z., K. E. Kunkel, and A. N. Samel, 2001: Development of a regional climate model for U.S. Midwest applications. Part I: Sensitivity to buffer zone treatment. J. Climate, 14, 4363-4378. 
—_ — R. Wilhelmson, J. Dudhia, and J. X. L. Wang, 2002: The WRF simulation of the 1993 central U.S. heavy rain: Sensitivity to cloud microphysics representation. Preprints, 16th Conf. on Hydrology, Orlando, FL, Amer. Meteor. Soc., 4.2. [Available online at http://ams.confex.com/ams/annual2002 /techprogram/paper_25616.htm.]

— , L. Li, A. Dai, and K. E. Kunkel, 2004a: Regional climate model simulation of summer precipitation diurnal cycle over the United States. Geophys. Res. Lett., 31, L24208, doi:10.1029/2004GL021054.

— $—$, K. E. Kunkel, M. Ting, and J. X. L. Wang, 2004b: Regional climate model simulation of U.S. precipitation during 1982-2002. Part I: Annual cycle. J. Climate, 17, 3510-3528.

—, J. Pan, K. E. Kunkel, J. X. L. Wang, E. C. Hunke, and W. H. Lipscomb, 2004c: Coupling the CWRF with the CICE for Arctic climate applications. Preprints, Fifth WRF/14th MM5 Users' Workshop. Boulder, CO, NCAR, 9.2.

— , and Coauthors, 2005a: Development of land surface albedo parameterization based on Moderate Resolution Imaging Spectroradiometer (MODIS) data. J. Geophys. Res., 110, D11107, doi:10.1029/2004JD005579.

—, H. Choi, K. E. Kunkel, Y. Dai, E. Joseph, J. X. L. Wang, and P. Kumar, 2005b: Development of the regional Climate-Weather Research and Forecasting Model (CWRF): Surface boundary conditions. Illinois State Water Survey Scientific Rep. 2005-01, 32 pp. [Available online at www.isws.illinois.edu /pubdoc/SR/ISWSSR2005-01.pdf.]

—, M. Xu, J. Zhu, K. E. Kunkel, and J. X. L. Wang, 2005c: Development of the regional Climate-Weather Research and Forecasting model (CWRF): Treatment of topography. Preprints, Sixth WRF/15th MM5 Users' Workshop, Boulder, CO, NCAR, 9.3.

—, H. Choi, K. E. Kunkel, Y. Dai, E. Joseph, J. X. L. Wang, and P. Kumar, 2005d: Surface boundary conditions for mesoscale regional climate models. Earth Interact., 9. [Available online at http:// EarthInteractions.org.]

_ , J. Pan, J. Zhu, K. E. Kunkel, J. X. L. Wang, and A. Dai, 2006a: Regional climate model downscaling of the U.S. summer climate and future change. J. Geophys. Res., 111, D10108, doi:10.1029/2005JD006685.

—, M. Xu, H. I. Choi, K. E. Kunkel, L. Rontu, J.-F. Geleyn, M. D. Müller, E. Joseph, and J. X. L. Wang, 2006b: Development of the regional Climate-Weather Research and Forecasting model (CWRF): Treatment of subgrid topography effects. Preprints, Seventh WRF Users' Workshop, Boulder, CO, NCAR, 7.3.
,-- , K. E. Kunkel, G. A. Grell, and J. Kain, 2007: Regional climate model simulation of U.S.-Mexico summer precipitation using the optimal ensemble of two cumulus parameterizations. J. Climate, 20, 5201-5207.

—, K. E. Kunkel, G. A. Meehl, R. G. Jones, and J. X. L. Wang, 2008a: Regional climate models downscaling analysis of general circulation models present climate biases propagation into future change projections. Geophys. Res. Lett., 35, L08709, doi:10.1029/2007GL032849.

_ , J. Zhu, K. E. Kunkel, M. Ting, and J. X. L. Wang, 2008b: Do CGCMs simulate the North American monsoon precipitation seasonal-interannual variability? J. Climate, 21, 4424-4448.

—, M. Xu, W. Gao, K. R. Reddy, K. Kunkel, D. L. Schmoldt, and A. N. Samel, 2012a: A distributed cotton growth model developed from GOSSYM and its parameter determination. Agron. J., 104, 661-674, doi:10.2134/agronj2011.0250.

,,,,,------ , and,$- 2012 \mathrm{~b}$ : Physical modeling of U.S. cotton yields and climate stresses during 1979-2005. Agron. J., 104, 675-683, doi:10.2134/agronj2011.0251.

Ling, T.-J., X.-Z. Liang, M. Xu, Z. Wang, and B. Wang, 2011: A multilevel ocean mixed-layer model for 2-dimension applications. Acta Oceanol. Sin., 33 (3), 1-10.

Liu, S., X.-Z. Liang, W. Gao, and H. Zhang, 2008: Climate-Weather Research and Forecasting model (CWRF) application in China: Domain optimization. Chin. J. Atmos. Sci., 32, 457-468.

_- W. Gao, M. Xu, X. Wang, and X.-Z. Liang, 2009: China summer precipitation using an optimal ensemble of cumulus parameterization schemes. Front. Earth Sci. China, 3, 248-257, doi:10.1007/ s11707-009-0022-8.

Lo, J. C.-F., Z.-L. Yang, and R. A. Pielke, Sr., 2008: Assessment of three dynamical climate downscaling methods using the Weather Research and Forecasting (WRF) model. J. Geophys. Res., 113, D09112, doi:10.1029/2007JD009216.

Mapes, B. E., T. T. Warner, M. Xu, and D. J. Gochis, 2004: Comparison of cumulus parameterizations and entrainment using domain-mean wind divergence in a regional model. J. Atmos. Sci., 61, 1284-1295.

Martin, G. M., D. W. Johnson, and A. Spice, 1994: The measurement and parameterization of effective radius of droplets in warm stratocumulus clouds. J. Atmos. Sci., 51, 1823-1842.

Mearns, L. O., and Coauthors, 2012: The North American Regional Climate Change Assessment 
Program: Overview of phase I results. Bull. Amer. Meteor. Soc., 93, 1337-1362.

Mukhopadhyay, P., S. Taraphdar, B. N. Goswami, and K. Krishnakumar, 2010: Indian summer monsoon precipitation climatology in a high-resolution regional climate model: Impacts of convective parameterization on systematic biases. Wea. Forecasting, 25, 369-387.

Murphy, J. M., D. M. H. Sexton, D. N. Barnett, G. S. Jones, M. J. Webb, M. Collins, and D. A. Stainforth, 2004: Quantification of modelling uncertainties in a large ensemble of climate change simulations. Nature, 430, 768-772.

Palmer, T. N., and Coauthors, 2004: Development of a European Multimodel Ensemble System for Seasonal-to-Interannual Prediction (DEMETER). Bull. Amer. Meteor. Soc., 85, 853-872.

— , F. J. Doblas-Reyes, A. Weisheimer, and M. J. Rodwell, 2008: Toward seamless prediction: Calibration of climate change projections using seasonal forecasts. Bull. Amer. Meteor. Soc., 89, 459-470.

,$- \ldots$, - and $—$ 2009: Reply. Bull. Amer. Meteor. Soc., 90, 1551-1554.

Park, S., and C. S. Bretherton, 2009: The University of Washington shallow convection and moist turbulence schemes and their impact on climate simulations with the Community Atmosphere Model. J. Climate, 22, 3449-3469.

Phillips, T. J., and Coauthors, 2004: Evaluating parameterizations in general circulation models: Climate simulation meets weather prediction. Bull. Amer. Meteor. Soc., 85, 1903-1915.

Scaife, A. A., C. Buontempo, M. Ringer, M. Sanderson, C. Gordon, and J. F. B. Mitchell, 2009: Toward seamless prediction: Calibration of climate change projections using seasonal forecasts. Bull. Amer. Meteor. Soc., 90, 1549-1551.

Shukla, J., R. Hagedorn, B. Hoskins, J. Kinter, J. Marotzke, M. Miller, T. N. Palmer, and J. Slingo, 2009: Revolution in climate prediction is both necessary and possible: A declaration at the World Modelling Summit for Climate Prediction. Bull. Amer. Meteor. Soc., 90, 175-178.

Skamarock, W. C., and Coauthors, 2008: A description of the Advanced Research WRF version 3. NCAR Tech. Note NCAR/TN-475+STR, 113 pp.

Takle, E. S., and Coauthors, 1999: Project to Intercompare Regional Climate Simulations (PIRCS): Description and initial results. J. Geophys. Res., 104 (D16), 19443-19461.

Tao, W.-K., and J. Simpson, 1989: Modeling study of a tropical squall-type convective line. J. Atmos. Sci., 46, 177-202.
—, J. Simpson, D. Baker, S. Braun, M.-D. Chou, B. Ferrier, D. Johnson, A. Khain, S. Lang, B. Lynn, C.-L. Shie, D. Starr, C.-H. Sui, Y. Wang, and P. Wetzel, 2003: Microphysics, radiation and surface processes in the Goddard Cumulus Ensemble (GCE) model. Meteor. Atmos. Phys., 82, 97-137.

Tselioudis, G., and C. Jakob, 2002: Evaluation of midlatitude cloud properties in a weather and a climate model: Dependence on dynamic regime and spatial resolution. J. Geophys. Res., 107, 4781, doi:10.1029/2002JD002259.

Tulich, S. N., G. N. Kiladis, and A. Suzuki-Parker, 2011: Convectively coupled Kelvin and easterly waves in a regional climate simulation of the tropics. Climate Dyn., 36, 185-203.

Uppala, S. M., D. P. Dee, S. Kobayashi, P. Berrisford, and A. J. Simmons, 2008: Towards a climate data assimilation system: Status update of ERA-Interim. ECMWF Newsletter, No. 115, ECMWF, Reading, United Kingdom, 12-18.

Vigaud, N., P. Roucou, B. Fontaine, S. Sijikumar, and S. Tyteca, 2011: WRF/ARPEGE-CLIMAT simulated climate trends over West Africa. Climate Dyn., 36, 925-944.

Wang, B., and H. Yang, 2008: Hydrological issues in lateral boundary conditions for regional climate modeling: Simulation of East Asian summer monsoon in 1998. Climate Dyn., 31, 477-490.

Wang, W., and Coauthors, 2012: ARW version 3 modeling system user's guide. NCAR, $384 \mathrm{pp}$. [Available online at www.mmm.ucar.edu/wrf/users/docs /user_guide_V3.3/ARWUsersGuideV3.pdf.]

Wang, X., and Coauthors, 2010: WRF-Chem simulation of East Asian air quality: Sensitivity to temporal and vertical emissions distributions. Atmos. Environ., 44, 660-669, doi:10.1016/j.atmosenv. 2009.11.011.

Wang, Y., L. R. Leung, J. L. McGregor, D.-K. Lee, W.-C. Wang, Y. Ding, and F. Kimura, 2004: Regional climate modeling: Progress, challenges, and prospects. J. Meteor. Soc. Japan, 82, 1599-1628.

Xu, M., X.-Z. Liang, W. Gao, K. R. Reddy, J. Slusser, and K. E. Kunkel, 2005: Preliminary results of the coupled CWRF-GOSSYM system. Remote Sensing and Modeling of Ecosystems for Sustainability II, W. Gao and D. Shaw, Eds., International Society for Optical Engineering (SPIE Proceedings, Vol. 5884), 588409, doi:10.1117/12.621017.

,,--- , J. Slusser, and K. Kunkel, 2006: Validation of the TUV module in CWRF using USDA-UVB network observations. Remote Sensing and Modeling of Ecosystems for Sustainability III, W. Gao and S. L. Ustin, Eds., International Society for Optical Engineering (SPIE Proceedings, Vol. 6298), 62980N, doi:10.1117/12.680122. 
Yuan, X., and X.-Z. Liang, 2011a: Evaluation of a Conjunctive Surface-Subsurface Process Model (CSSP) over the contiguous United States at regional-local scales. J. Hydrometeor., 12, 579-599.

- , and — 2011b: Improving cold season precipitation prediction by the nested CWRFCFS system. Geophys. Res. Lett., 38, L02706, doi:10.1029/2010GL046104.

— _ _ , and E. Wood, 2012: WRF ensemble downscaling seasonal forecasts of China winter precipitation during 1982-2008. Climate Dyn., in press, doi:10.1007/s00382-011-1241-8

Zeng, M.-J., W.-S. Lu, X.-Z. Liang, and X.-L. Wang, 2008a: Ensemble forecast experiment on precipitation in summer by CWRF numeric model. Plateau Meteor., 27 (6), 1-11.
,,,--- H. Wu, M. Pu, and D. Yin, 2008b: Analysis of temperature structure for persistent disastrous freezing rain and snow over southern China in early 2008. Acta Meteor. Sin., 66, 1043-1052.

Zhang, Y., V. Dulière, P. W. Mote, and E. P. Salathé, 2009: Evaluation of WRF and HadRM mesoscale climate simulations over the U.S. Pacific Northwest. J. Climate, 22, 5511-5526.

Zhu, J., and X.-Z. Liang, 2005: Regional climate model simulation of U.S. soil temperature and moisture during 1982-2002. J. Geophys. Res., 110, D24110, doi:10.1029/2005JD006472.

— tion of U.S. precipitation and surface air temperature during 1982-2002: Interannual variation. J. Climate, 20, 218-232.

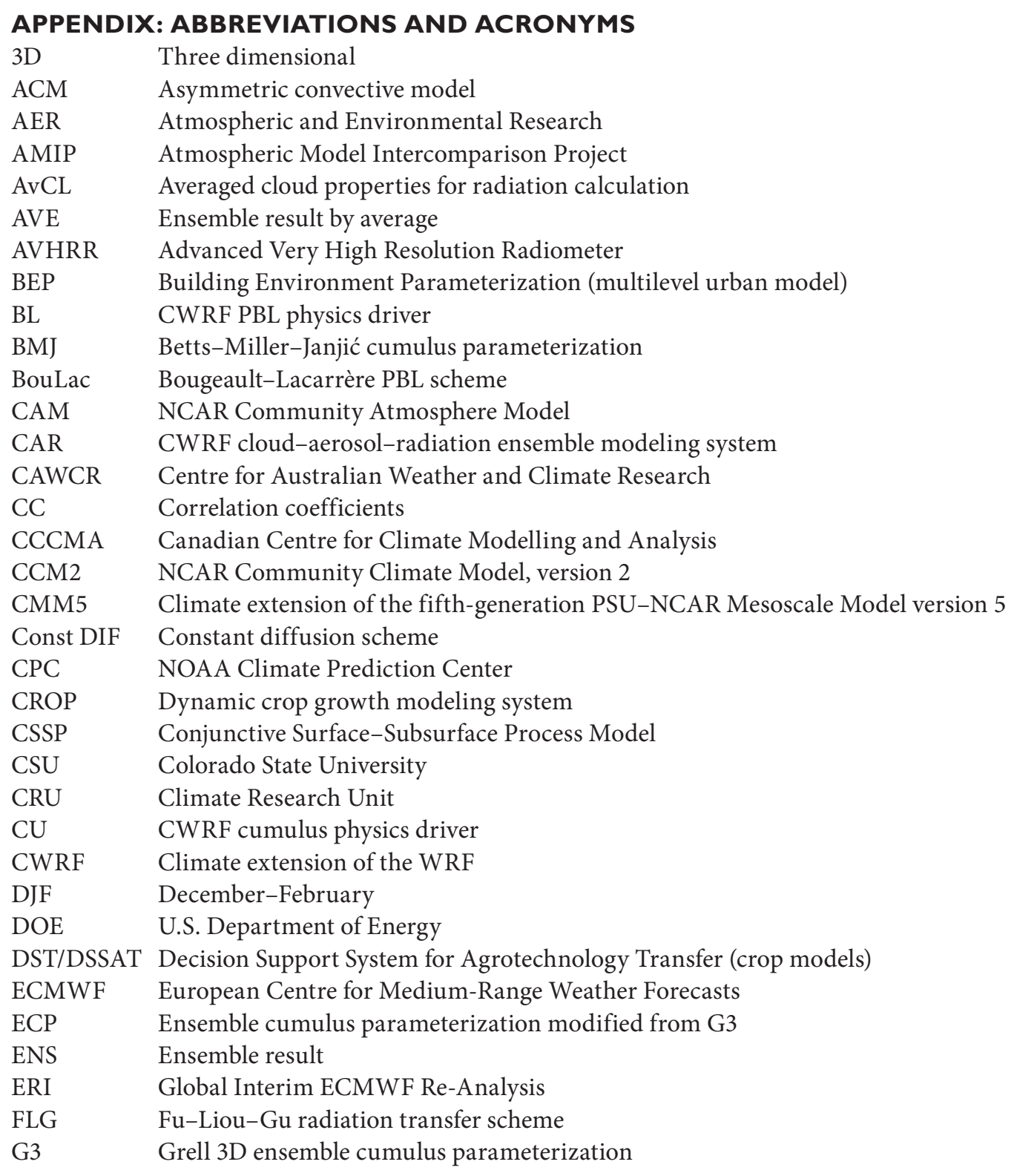

3D

ACM

AER

AMIP

AvCL

AVE

AVHRR

BEP

BL

BMJ

BouLac

CAM

CAR

CAWCR

CC

CCCMA

CCM2

CMM5

Const DIF

$\mathrm{CPC}$

CROP

CSSP

CSU

CRU

CU

CWRF

DJF

DOE

DST/DSSAT

ECMWF

ECP

ENS

ERI

FLG

G3

Three dimensional

Asymmetric convective model

Atmospheric and Environmental Research

Atmospheric Model Intercomparison Project

Averaged cloud properties for radiation calculation

Ensemble result by average

Advanced Very High Resolution Radiometer

Building Environment Parameterization (multilevel urban model)

CWRF PBL physics driver

Betts-Miller-Janjić cumulus parameterization

Bougeault-Lacarrère PBL scheme

NCAR Community Atmosphere Model

CWRF cloud-aerosol-radiation ensemble modeling system

Centre for Australian Weather and Climate Research

Correlation coefficients

Canadian Centre for Climate Modelling and Analysis

NCAR Community Climate Model, version 2

Climate extension of the fifth-generation PSU-NCAR Mesoscale Model version 5

Constant diffusion scheme

NOAA Climate Prediction Center

Dynamic crop growth modeling system

Conjunctive Surface-Subsurface Process Model

Colorado State University

Climate Research Unit

CWRF cumulus physics driver

Climate extension of the WRF

December-February

U.S. Department of Energy

T Decision Support System for Agrotechnology Transfer (crop models)

European Centre for Medium-Range Weather Forecasts

Ensemble cumulus parameterization modified from G3

Ensemble result

Global Interim ECMWF Re-Analysis

Fu-Liou-Gu radiation transfer scheme

Grell 3D ensemble cumulus parameterization 


\begin{tabular}{|c|c|}
\hline GCE & Goddard Cumulus Ensemble parameterization \\
\hline GCM & General Circulation Model \\
\hline GD & Grell-Dévényi ensemble cumulus parameterization \\
\hline GFDL & Geophysical Fluid Dynamics Laboratory \\
\hline GFS & NOAA Global Forecast System \\
\hline GR & Grell cumulus parameterization \\
\hline GSFC & NASA Goddard Space Flight Center \\
\hline GSY & Gossypium cotton growth model \\
\hline HIR & High-resolution PBL scheme \\
\hline ISCCP & International Satellite Cloud Climatology Project \\
\hline JJA & June-August \\
\hline Kessler & Kessler microphysics scheme \\
\hline L2.5 TKE & 2.5-order TKE diffusion scheme \\
\hline L2 3D DEF & 2-order 3D deformation and stability diffusion scheme \\
\hline LBCs & Lateral boundary conditions \\
\hline LETKF & Local ensemble transform Kalman filter \\
\hline Lin & Lin et al. microphysics scheme \\
\hline LW & Longwave \\
\hline MAM & March-May \\
\hline MISC & Miscellaneous (obsolete) radiation schemes \\
\hline MISR & Multiangle Imaging SpectroRadiometer \\
\hline MIT & Massachusetts Institute of Technology \\
\hline MODIS & Moderate Resolution Imaging Spectroradiometer \\
\hline Morrison & Morrison et al. two-moment microphysics scheme \\
\hline MP & CWRF microphysics driver \\
\hline MRF & Medium-Range Forecast Model \\
\hline MYJ & Mellor-Yamada-Janjić PBL scheme \\
\hline MYNN & Mellor-Yamada PBL scheme modified by Nakanishi-Niino \\
\hline NAM & North American monsoon \\
\hline NARCCAP & North American Regional Climate Change Assessment Program \\
\hline NASA & National Aeronautics and Space Administration \\
\hline NCAR & National Center for Atmospheric Research \\
\hline NCEP & National Centers for Environmental Prediction \\
\hline NKF & New Kain-Fritsch cumulus parameterization \\
\hline NOAA & National Oceanic and Atmospheric Administration \\
\hline Noah & NCAR-NCEP unified land surface model \\
\hline NSAS & New Simplified Arakawa-Schubert scheme \\
\hline NWP & Numerical weather prediction \\
\hline OBS & Observed \\
\hline OCN & SfcExt for ocean characteristics \\
\hline OPT & Ensemble result by optimization \\
\hline ORO & Module for orographic turbulence stress and gravity wave drag \\
\hline OSU & Oregon State University \\
\hline PBL & Planetary boundary layer \\
\hline PR & Precipitation \\
\hline PSU & Pennsylvania State University \\
\hline PX & Pleim-Xiu land surface scheme \\
\hline QNSE & Quasi-normal scale elimination PBL scheme \\
\hline $\mathrm{R}-2$ & NCEP-DOE AMIP-II Reanalysis \\
\hline RA & CWRF radiation physics driver \\
\hline RadExt & $\begin{array}{l}\text { CWRF module for external radiative conditions (solar constant, atmospheric gas volume mixing } \\
\text { ratios, aerosol distributions) }\end{array}$ \\
\hline $\mathrm{RCM}$ & Regional climate model \\
\hline
\end{tabular}




$\begin{array}{ll}\text { RMS/rms } & \text { Root-mean-square } \\ \text { RUC } & \text { Rapid Update Cycle } \\ \text { SAS } & \text { Simplified Arakawa-Schubert scheme } \\ \text { SBCs } & \text { Surface boundary conditions } \\ \text { SF } & \text { CWRF surface physics driver } \\ \text { SfcExt } & \text { CWRF module for external surface and subsurface conditions } \\ \text { Slab } & \text { 5-layer thermal diffusion model } \\ \text { SM200 } & \text { Top 2-m soil moisture } \\ \text { SOM } & \text { Simple ocean model } \\ \text { SON } & \text { September-November } \\ \text { SST } & \text { SfcExt for sea surface temperature } \\ \text { SW } & \text { Shortwave } \\ \text { SWD } & \text { Downwelling shortwave } \\ \text { T2M } & \text { 2-m temperature } \\ \text { Tao } & \text { Tao et al. microphysics scheme } \\ \text { TDK } & \text { Tiedtke cumulus scheme } \\ \text { TEMF } & \text { Total energy-mass flux boundary layer scheme (Angevine et al. 2001) } \\ \text { Thompson } & \text { Thompson et al. microphysics scheme } \\ \text { TKE } & \text { Turbulent kinetic energy } \\ \text { TS } & \text { Time series } \\ \text { UCM } & \text { Single layer urban canopy model } \\ \text { UOM } & \text { Multilevel upper-ocean model } \\ \text { U.S. } & \text { United States } \\ \text { USGS } & \text { U.S. Geological Survey } \\ \text { UV } & \text { Ultraviolet radiation } \\ \text { UW } & \text { University of Washington } \\ \text { VEG } & \text { SfcExt for vegetation characteristics } \\ \text { WDM6 } & \text { WRF Double-Moment 6-class microphysics scheme } \\ \text { WSM5 } & \text { WRF Single-Moment 5-class microphysics scheme } \\ \text { WSM6 } & \text { WRF Single-Moment 6-class microphysics scheme } \\ \text { WRF } & \text { Weather Research and Forecasting model } \\ \text { WRFG } & \text { WRF version 2 with the GD cumulus scheme } \\ \text { WSM3 } & \text { WRF Single-Moment 3-class scheme } \\ \text { YSU } & \text { Yonsei University } \\ \text { Zhao } & \text { Eta microphysics scheme } \\ \text { ZML } & \text { Zhang-McFarlane-Liang cumulus scheme } \\ & \end{array}$




\section{Radar and Atmospheric Science: A Collection of Essays in Honor of David Atlas}

Edited by Roger M. Wakimoto and Ramesh Srivastava

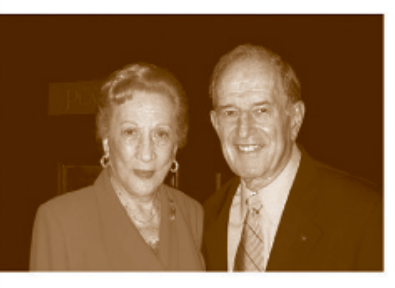

This monograph pays tribute to one of the leading scientists in meteorology, Dr. David Atlas. In addition to profiling the life and work of the acknowledged "Father of Radar Meteorology," this collection highlights many of the unique contributions he made to the understanding of the forcing and organization of convective systems, observation and modeling of atmospheric turbulence and waves, and cloud microphysical properties, among many other topics. It is hoped that this text will inspire the next generation of radar meteorologists, provide an excellent resource for scientists and educators, and serve as a historical record of the gathering of scholarly contributions honoring one of the most important meteorologists of our time.

Radar and Atmospheric Science: A Collection of Essays in Honor of David Atlas Aug 2003. Meteorological Monograph Series, Vol. 30, No. 52; 270 pp, hardbound; ISBN 1-878220-57-8; AMS code MM52.

Price $\$ 100.00$ list $/ \$ 80.00$ member

To place an order point your Web browser to www.ametsoc.org/amsbookstore 